\title{
$1 \quad$ NMR study of choline chloride-based deep eutectic solvents
}

2 Ignacio Delso ${ }^{\mathbf{a}}$, Carlos Lafuente ${ }^{\mathbf{b}}$, José Muñoz-Embid ${ }^{\mathbf{b}}$, Manuela Artal ${ }^{\mathbf{b}, *}$

3 a Instituto de Síntesis Química y Catálisis Homogénea (ISQCH) and Servicio de

4 Resonancia Magnética Nuclear, Centro de Química y Materiales de

5 Aragón (CEQMA), Universidad de Zaragoza-CSIC, Spain

$6 \quad{ }^{\mathrm{b}}$ Departamento de Química Física, Universidad de Zaragoza, Zaragoza, Spain

$7 \quad *$ Corresponding author. Tel: +34876553765. e-mail: $\underline{\text { martal@unizar.es }}$

\section{Abstract}

10 Nowadays, the eutectic liquids (DESs) are considered an adequate alternative to the traditional solvents. Therefore, there is an increasing interest in the study of the structure, properties and applications of these mixtures. In this paper, several NMR spectroscopic techniques have been used in order to evaluate the molecular structure of three ternary DESs, composed of choline chloride, urea or glycerol or ethylene glycol, and water. The use of routine and non-routine NMR techniques, such as ${ }^{1} \mathrm{H},{ }^{13} \mathrm{C}$, correlation experiments, NOESY, ROESY, and diffusion experiments gave us some important evidences pointing to a supramolecular structure of the DES, which may be the origin of their particular behaviour. The mixture containing ethylene glycol shows the feeblest structure. In these ternary solvents, the water is found within the structure that is still retained when DESs are diluted at $10 \% \mathrm{wt}$. 
22 Keywords: Deep Eutectic Solvents; NMR spectroscopy; Self-diffusion coefficients;

23 Choline chloride; Urea; Glycerol; Ethylene Glycol.

\section{Introduction}

The full solvents elimination in the laboratory or industry is an unreasonable objective due to the different roles exerted by them in the physicochemical procedures. The environmental problems derived by use of traditional ones, usually volatile organic compounds (VOCs), have turned the development of new eco-friendly products a priority line in the Green Chemistry. According to the IUPAC [1], this chemistry area "deals with the design of chemical products and processes that reduce or eliminate the use or generation of substances hazardous to humans, animals, plants, and the environment". Because of this, the synthesis processes should include: (i) non-toxic and renewable substances; (ii) a maximum economy of materials avoiding by-products and wastes; (iii) minimum requirements of energy (temperature and pressure); and (iv) minimum risks respect to possible accidents. In addition, the products formed should be able to decompose into non-harmful ones when their function has finished.

Several VOCs substitutes have been proposed such as supercritical fluids, biomass based solvents, or low temperature transition liquids (LTTMs) [2-5]. In the latter group, the ionic liquids (ILs) and the deep eutectic solvents (DESs) are included. Both type of fluids are used for applications in similar fields. However, there are important differences between them. The high toxicity and economic cost of some of ILs have caused the ionic liquids are not currently catalogued as green solvents [6,7]. By contrast, the composition and the synthesis procedure of the DESs make them eco-friendly solvents. The term DES was proposed by Abbott et al. [8] to refer to mixtures (two or more substances) with a melting temperature, $T_{m}$, lower to that of the individual components. It is necessary to 
clarify that the composition of the eutectic mixtures studied in the literature does not always correspond to that of the eutectic point. In bibliography, ionic and non-ionic eutectic solvents have been reported; some of them are hydrophilic liquids and others have hydrophobic behavior [9-13]. However, the commun feature is the ability of the components of the mixture to establish an important hydrogen-bond network. So, DESs contain both hydrogen bond acceptors (HBA) and donors (HBD) substances. Natural deep eutectic solvent (NADES) is a term frequently used in the literature when the eutectic is composed by metabolites (sugars, organic acids, amines,...) [14]. Moreover, if the components are active pharmaceutical ingredients (APIs), the term therapeutic deep eutectic solvent (THEDES) is applied by some authors [15]. The issue of the nomenclature is being a controversial subject [5]. In this paper, the acronym DES will be used to refer to the studied mixtures.

Two methods are mostly used for the DESs synthesis from the adequate molar ratios of HBA and HBD components: heating with agitation at soft temperature (about $323 \mathrm{~K}$ ), and dissolution of the components in water and subsequent evaporation [16]. In these processes, no chemical reaction is involved so the efficiency is total, no waste is produced, and the energetic cost is low; three basic issues in the Green Chemistry. In relation to the environmental analysis, these compounds are usually more biodegradable than other solvents but the toxicity profiles are varied. Caution must be applied in their classification because both the toxicity of the individual components and possible synergistic effects between them must be evaluated [17]. For instance, choline chloride-based DESs are moderatly toxic, relatively harmless or practically harmless depending of the HBD compound [18-20]. It has also been observed that certain DESs can be used as antibacterial, antifungal or anticancer agents; therefore, their toxicity become into an advantage $[3,21]$. One mayor drawback for the implementation of these solvents in the 
industrial processes is the high viscosity values of the mostly of DESs [9]. However, this property can be modulated using the plasticizer effect of the water; the addition of small amounts increases substantially the fluidity of the liquid [22,23]. The hygroscopic capacity of several ChCl-based DESs has been studied by Chen et al [24].

The research to date has tended to focus on applications of these liquids rather than on their chemical characterization. As a result, aspects related to the structure of the DESs and the role of the water in the aqueous eutectics are not well elucidated. Nevertheless, some papers have been published. For similar mixtures to those included herein, the selfdiffusion coefficients at several temperatures were determined by D'Agostino et al. $[25,26]$ from PFG-NMR spectroscopy. Recently, the micro-segregation in the diluted eutectic has been observed using Brillouin and ${ }^{1} \mathrm{H}$ NMR techniques by Posada et al. [27] The effect of the water in the nanostructure has been studied with neutron total scattering by Hammond et al. [28] They have evidenced the existence of clusters even at high dilution. Other authors [29-31] have performed quantum calculations and molecular dynamics simulations in order to analyse the hydrogen bonding network. Finally, for eutectics different from those studied in this work, a supramolecular structure has been detected from several spectroscopic experiments [14,16,32,33].

The aim of this paper is to examine the molecular structure of three deep eutectic solvents whose composition includes choline chloride, urea or glycerol or ethylene glycol, and water. We evaluate the interactions stablished between the three components of each mixture from several NMR spectroscopic studies performed at $298 \mathrm{~K}$. In addition, we calculate the self-diffusion coefficients of the different species and compare with those of the literature. From these results, we analyse the role of the water in these aqueous eutectics. 


\subsection{Materials}

Choline chloride, $[\mathrm{Ch}] \mathrm{Cl}$, (purity $\geq 98 \%$ ) provided by Sigma-Aldrich was used as hydrogen bond accept (HBA) for all DESs studied in this work. This compound was dried under vacuum during several hours. The several hydrogen bond donors (HBDs) were: urea, $U$, (purity $\geq 99.5$ ) acquired from Panreac, and glycerol, Gly, (purity $\geq 99.5 \%$ ) and ethylene glycol, EG, (purity $\geq 99 \%$ ) from Sigma-Aldrich. Moreover, distilled deionized water, W, with resistivity less than $18.2 \mu \mathrm{S} \cdot \mathrm{cm}^{-1}$ was utilized. A Sartorius balance BP210S $( \pm 0.1 \mathrm{mg})$ was used to weigh the compounds in adequately proportion: 1:2 $([\mathrm{Ch}] \mathrm{Cl}: \mathrm{HBD})$ mole ratio and a water content $<10.5 \% \mathrm{wt}$. The liquids were obtained by heating to $50^{\circ} \mathrm{C}$ under magnetic agitation until a homogeneous liquid is formed. The characteristics of the ternary eutectic mixtures are listed in Table S1.

\subsection{Methods}

NMR measurements were performed on a Bruker AVANCE operating at $400 \mathrm{MHz}$ for ${ }^{1} \mathrm{H}$ using a direct 5 -mm broadband probe with $\mathrm{z}$-axis gradients. The sample temperature was established at $298 \mathrm{~K}$. The chemical shifts were referenced to TMS as external standard. ${ }^{1} \mathrm{H}-\mathrm{NMR}$ spectra were recorded with a standard one-pulse sequence with $90^{\circ}$ flip angle for excitation (Bruker pulse program $\mathrm{zg}$ ), with a spectral width of 16 ppm, centred at $5 \mathrm{ppm}, 16 \mathrm{~K}$ data points and relaxation time fixed to $30 \mathrm{~s} .8$ scans were acquired for each spectrum. ${ }^{13} \mathrm{C}$-NMR spectra were recorded with an APT sequence (Bruker pulse program jmod), with a spectral width of $240 \mathrm{ppm}$, centred at $110 \mathrm{ppm}, 64$ $\mathrm{K}$ data points and relaxation time fixed to $2 \mathrm{~s} .256$ scans were acquired for each spectrum. Signal assignation was performed with routine gradient selected DQF-COSY, ${ }^{1} \mathrm{H}-{ }^{13} \mathrm{C}$ HSQC and ${ }^{1} \mathrm{H}^{13} \mathrm{C}$ HMBC (Bruker pulse programs cosygpmfaf, hsqcedetgp and 
hmbclpndqf respectively) employing optimized $90^{\circ}$ angle pulses. NOESY experiments were carried out using a gradient selected NOESY sequence (Bruker pulse program noesygpph) with a spectral width of $4 \mathrm{ppm}$ centred at $4 \mathrm{ppm}$, with $128 \mathrm{t} 1$ increments and 8 scans for each increment. Mixing time $\left(t_{m i x}\right)$ was adjusted as described for each case. ROESY experiments were measured using a non-gradient selected sequence (Bruker pulse program roesyph) with the suitable spectral widths and centers, with 128 t1 increments and 16 scans for each increment. Diffusion experiments were performed by using a stimulated echo sequence with bipolar gradient pulses (Bruker pulse program stebpgp1s) with a spectral width of $16 \mathrm{ppm}$ centred at $5 \mathrm{ppm}$, and $16 \mathrm{~K}$ data points. Big delta was set to $200 \mathrm{~ms}$ and $16 \mu$ s for small delta. Gradient pulses strength were varied over 32 steps ( 8 transients each) to obtain a $95 \%$ decrease in the resonance intensity at the largest gradient amplitudes. The self-diffusion coefficients, $D$, were calculated by fitting the intensity of each signal to the exponential function:

$$
I(g)=I_{0} \exp \left[-D \gamma_{H}^{2} g^{2} \delta^{2}(\Delta-\delta / 3)\right]
$$

where $I(g)$ is the resonance intensity measured for a given gradient strength, $g ; I_{0}$ is the NMR signal in the absence of the gradient pulse; $\gamma_{H}$ is the gyromagnetic ratio of the hydrogen nucleus; $\delta$ is the duration of the bipolar gradient pulse; and $\Delta$ is the observation time.

\section{Results and discussion}

In this section, the chemical structure of each eutectic is analysed. First, we present the ${ }^{1} \mathrm{H}$ and ${ }^{13} \mathrm{C}$ spectra that allow to identify the different atoms present in the mixtures. Second, we used the Nuclear Overhauser Effect SpectroscopY (NOESY) technique in order to examine the interactions that may be associated to the formation of the liquid phase and the high stability of the DESs, supported by other experiments such as ROESY. 
Third, we calculate the mobility of the species from Diffusion-Ordered SpectroscopY

143 (DOSY) spectra. Last, to evaluate the effect of addition of water on the eutectic structure,

144 NMR experiments for two dilutions of each DESs $\left(10 \%\right.$ and $\left.90 \% \mathrm{D}_{2} \mathrm{O}\right)$ are included.

145 Throughout this section, we will use the following abbreviations: aliphatic hydrogens of 146 the choline, $\mathrm{Ch}^{+}$; hydroxyl hydrogens of the choline, $\mathrm{OH}-\mathrm{Ch}^{+}$; aliphatic hydrogens of 147 the HBD compound, Gly, or EG; mobile hydrogens of the HBD compound, such as hydroxyl, $\mathrm{OH}-\mathrm{Gly}$ or $\mathrm{OH}-\mathrm{EG}$ or aminic hidrogens from urea $\mathrm{NH}_{2}-\mathrm{U}$; water, $\mathrm{W}$; and partially deuterated water, HDO. In addition, in each section a particular notation will be used for each individual hydrogen or carbon. We have chosen the choline chloride:glycerol:water as a model for a more detailed study, due to the higher number of hydroxyl and aliphatic hydrogens.

\section{1 [Ch]Cl:Gly:W}

In the ${ }^{1} \mathrm{H}-\mathrm{NMR}$ spectrum (Fig. 1a), the signals of the methylene group bounded to the choline nitrogen, $\mathrm{CH}_{2}-\mathrm{N}^{+}(\mathrm{c})$, and those of two hydroxylmethylenes of the glycerol (f), are overlapping; the rest are perfectly separated: $\delta=3.04\left(\mathrm{~s}, 9 \mathrm{H}, \mathrm{H}_{\mathrm{d}}\right), 3.23-3.33(\mathrm{~m}$, $\left.4 \mathrm{H}, \mathrm{H}_{\mathrm{f}}\right), 3.33-3.43\left(\mathrm{~m}, 6 \mathrm{H}, \mathrm{H}_{\mathrm{f}}, \mathrm{H}_{\mathrm{c}}\right), 3.44-3.53\left(\mathrm{~m}, 2 \mathrm{H}, \mathrm{H}_{\mathrm{g}}\right), 3.76-3.85\left(\mathrm{~m}, 2 \mathrm{H}, \mathrm{H}_{\mathrm{b}}\right), 4.26$ $\left(\mathrm{s}, 2.0 \mathrm{H}, \mathrm{H}_{\mathrm{i}}\right), 4.73\left(\mathrm{t}, \mathrm{J}=5.0 \mathrm{~Hz}, 4 \mathrm{H}, \mathrm{H}_{\mathrm{e}}\right), 4.82\left(\mathrm{~d}, \mathrm{~J}=4.8 \mathrm{~Hz}, 2 \mathrm{H}, \mathrm{H}_{\mathrm{h}}\right), 5.08(\mathrm{t}, \mathrm{J}=4.7$ $\mathrm{Hz}, 1 \mathrm{H}, \mathrm{H}_{\mathrm{a}}$ ). The ${ }^{13} \mathrm{C}$ spectrum was the expected (Fig. 1b) with: $\delta=53.9$ (t, J = 3.0 Hz, $\left.\mathrm{C}_{\mathrm{d}}\right), 55.9\left(\mathrm{C}_{\mathrm{b}}\right), 63.1\left(\mathrm{C}_{\mathrm{f}}\right), 67.5\left(\mathrm{C}_{\mathrm{c}}\right), 72.6\left(\mathrm{C}_{\mathrm{g}}\right)$. From the ${ }^{1} \mathrm{H}-\mathrm{NMR}$ spectrum integration, the calculated composition $(u(x)=0.05)$ is choline chloride/glycerol/ water in molar ratio 1:1.96:0.97. The calculated water content is: $5.3 \% \mathrm{wt}$.

The addition of $10 \%$ of deuterated water, $\mathrm{D}_{2} \mathrm{O}$, in the ternary eutectic does not causes significant changes in the ${ }^{1} \mathrm{H}-\mathrm{NMR}$ signals of the aliphatic hydrogens but those of the hydroxyl ones widen and decrease the value of their integral (Fig. S1a). Adding 90\% 
$\mathrm{D}_{2} \mathrm{O}$, the resolution of the spectrum improves and a single signal corresponding to HDO is observed. The pronounced displacement of aliphatic signals may indicate a substantial variation of the chemical environment showing the loss of the H-bond network. On the other hand, the $10 \%$ dilution causes small variations in the ${ }^{13} \mathrm{C}$ spectrum being the signals of glycerol the most modified. Higher differences of chemical shift between neat and 90

(a)

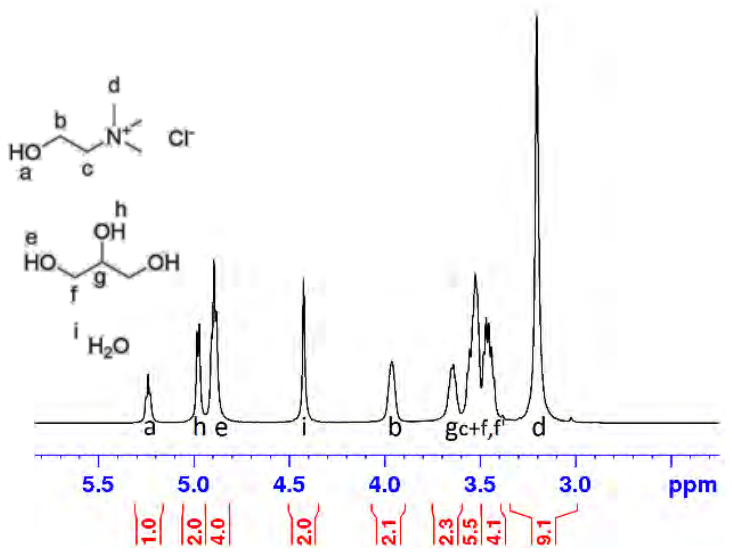

(b)

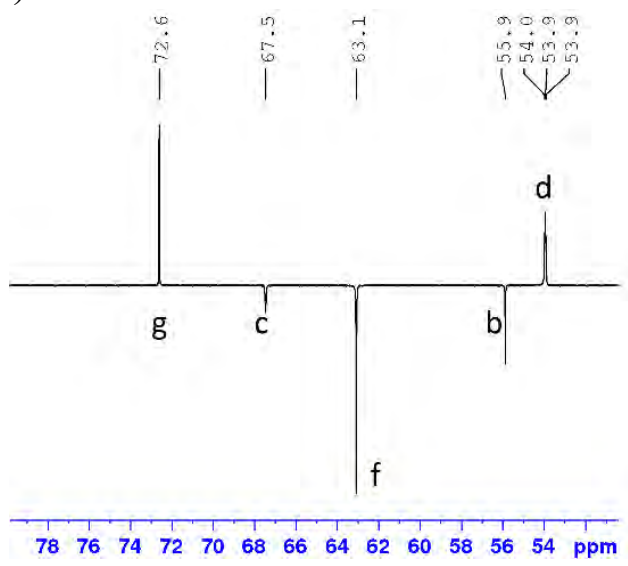

175

Figure 1. [Ch]Cl:Gly:W spectra at $298 \mathrm{~K}$ : (a) ${ }^{1} \mathrm{H}-\mathrm{NMR}$ (b) ${ }^{13} \mathrm{C}-\mathrm{NMR}$.

Figure 2 shows the NOESY spectra for $t_{m i x}=50$ (Fig. 2a) and $t_{m i x}=800 \mathrm{~ms}$ (Fig. 2b); spectra for intermediated times are reported in Fig. S2. With the longer mixing time appear crosspeaks among almost all the proton signals (mobile and aliphatic hydrogens), what evidences the existence of interaction between the protons from the different species throughout space. It can be observed strong nOe couplings between choline and glycerol, both aliphatic and hydroxyl hydrogens, as well as choline with water (being the most intense ones coming from the methyl groups). No nOe signals were observed between glycerol aliphatic hydrogens and water. In the case of mobile protons, in these spectra, $a$ priori, it is not possible to distinguish whether the signals are coming from chemical exchange or nuclear Overhauser effect. However, the increasing intensity of these 
crosspeaks with the mixing time suggests an important contribution of nOe to signals,

187

188

189

190

191

192

193

194

195

196

197

198

199

200

201

202

203

204

205

besides the chemical exchange. Spin diffusion effects were discarded when a ROESY experiments were measured, showing strong negative ROE crosspeaks between choline methyl groups and all the proton signals from the other species, as well as less intense signals from the glycerol hydrogens (Fig S3).Through the study of the enhancement of nOe signals with mixing time a tentative model of interaction between the hydrogens of the three species can be represented, as shown in Fig. 2c; the thicker the line the more intense the interaction. Moreover, the spectrum obtained after six months (Fig. S2c) was similar to that performed just after synthesis (Fig. S2a); so, we can conclude that the structure is stable.

(a)

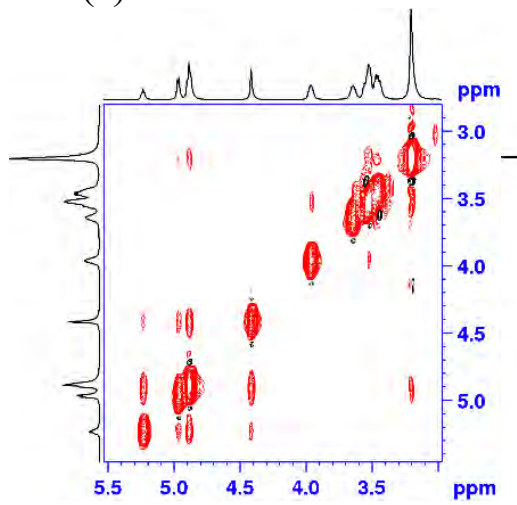

(b)

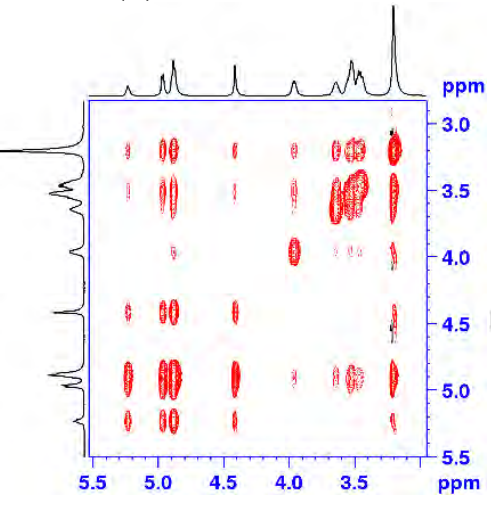

(c)

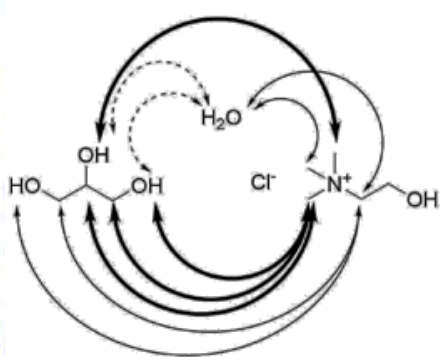

Figure 2. NOESY spectra of [Ch]Cl:Gly:W at $298 \mathrm{~K}$ and at different mixing times: (a) $t_{m i x}=50 \mathrm{~ms}$, and (b) $t_{m i x}=800 \mathrm{~ms}$; (c) H-H interactions representation.

In the NOESY experiment of the $10 \%$ diluted sample (Fig. 3a), the negative nOes previously observed between the methyl groups of the choline and the Gly continue. In addition, signals of exchange for $\mathrm{OH}-\mathrm{Ch}^{+} / \mathrm{W}$ and $\mathrm{OH}-\mathrm{Gly} / \mathrm{W}$ appear. On the other hand, the interactions $\mathrm{OH}-\mathrm{Ch}^{+} / \mathrm{Gly}, \mathrm{OH}-\mathrm{Gly} / \mathrm{Gly}$, and $\mathrm{OH}-\mathrm{Ch}^{+} / \mathrm{Ch}^{+}$show nOes of sign positive. These results suggest that the eutectic maintains its properties even though the viscosity has decreased. By increasing the dilution to $90 \%$, the negative nOes 

them.

(a)

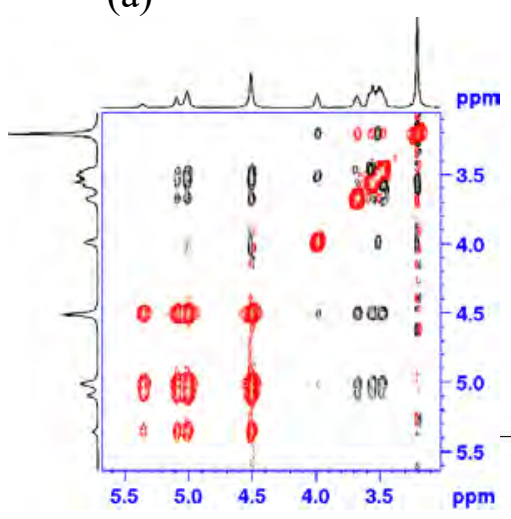

(b)

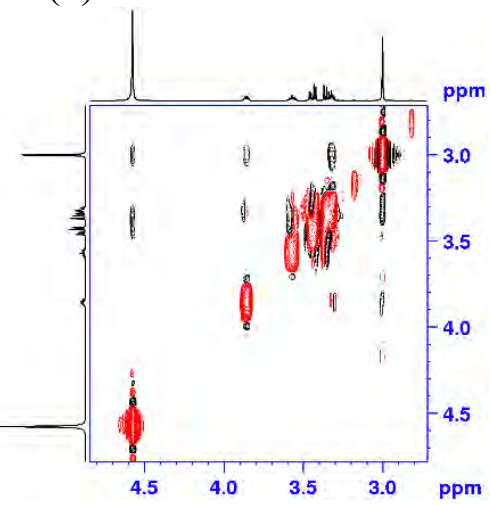

211

212

Figure 3. NOESY spectra of [Ch]Cl:Gly:W at $298 \mathrm{~K}$, at $t_{m i x}=800 \mathrm{~ms}$, and at several dilutions: (a) $10 \% \mathrm{D}_{2} \mathrm{O}$, and (b) $90 \% \mathrm{D}_{2} \mathrm{O}$.

DOSY spectrum for the ternary DES (Fig. 4a) shows five clearly differentiated traces whose numeric analysis allows calculating the self-diffusion coefficients (Table 1). These traces correspond to (from higher to lower $D$ ): $\mathrm{W}, \mathrm{OH}-\mathrm{Gly}, \mathrm{Gly}, \mathrm{OH}-\mathrm{Ch}^{+}$and $\mathrm{Ch}^{+}$. Obviously, water has the highest $D$ value but is much lower than those obtained for the eutectic containing urea (as seen below) or for free water: $D_{\mathrm{H}_{2} \mathrm{O}}(T=298.15 \mathrm{~K})=230 \cdot 10^{-}$ ${ }^{11} \mathrm{~m}^{2} \cdot \mathrm{s}^{-1}$ [34]. Highlight that the diffusivity for the rest of species (especially in the case of hydroxyl hydrogens) is very similar indicating the presence of a very low mobility due to a strong interaction between glycerol and choline, and with their mobile hydrogens. This fact has already been reported in the literature [26] and our calculated values of $D$ agree with those. Again, we can suggest that the eutectic has an orderly and stable supramolecular structure. When $\mathrm{D}_{2} \mathrm{O}$ diluted samples were measured, very similar behaviour was observed for the $10 \%$ diluted sample (Fig. $4 \mathrm{~b}$ ), with similar $D$ values for all type of hydrogens, except those from water. This result shows that the supramolecular 
226 structure is conserved. However, for the 90\% diluted sample (Fig. 4c), the self-diffusion

227 coefficients correspond to those of individual and solvated molecules.

228

$229 \quad$ (a)

(b)

(c)

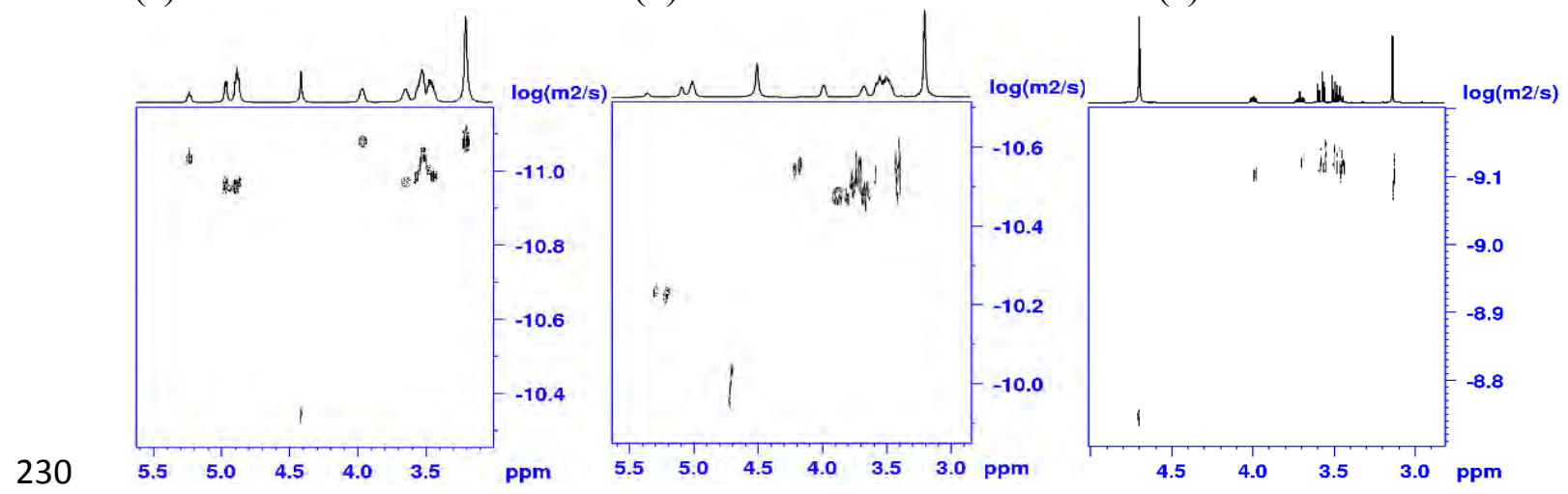

231 Figure 4. DOSY experiments of [Ch]Cl:Gly:W at 298 K. (a) neat eutectic; (b) $10 \%$ of $232 \mathrm{D}_{2} \mathrm{O}$; and (c) $90 \%$ of $\mathrm{D}_{2} \mathrm{O}$.

233 Table 1 . The self-diffusion coefficients, $D$, at $298 \mathrm{~K}$ of the several species in the non234 aqueous and aqueous DES with glycerol.

\begin{tabular}{|c|c|c|c|c|c|}
\hline DES & $\begin{array}{c}10^{11} D_{\mathrm{Ch}^{+}} \\
/ \mathrm{m}^{2} \cdot \mathrm{s}^{-1}\end{array}$ & $\begin{array}{c}10^{11} D_{\mathrm{OH}-\mathrm{Ch}^{+}} \\
/ \mathrm{m}^{2} \cdot \mathrm{s}^{-1}\end{array}$ & $\begin{array}{c}10^{11} D_{G l y} \\
/ \mathrm{m}^{2} \cdot \mathrm{s}^{-1}\end{array}$ & $\begin{array}{c}10^{11} D_{\mathrm{OH}-G l y} \\
/ \mathrm{m}^{2} \cdot \mathrm{s}^{-1}\end{array}$ & $\begin{array}{c}10^{11} D_{\mathrm{H}_{2} \mathrm{O}} \\
/ \mathrm{m}^{2} \cdot \mathrm{s}^{-1}\end{array}$ \\
\hline [Ch]Cl:Gly & $0.38^{\mathrm{a}}$ & $0.38^{\mathrm{a}}$ & $0.52^{\mathrm{a}}$ & $0.52^{\mathrm{a}}$ & --- \\
\hline \multirow[t]{2}{*}{ [Ch]Cl:Gly:W } & 0.80 & 0.86 & 0.97 & 1.03 & 3.55 \\
\hline & $0.7^{\mathrm{b}}$ & $0.7^{\mathrm{b}}$ & $0.7^{\mathrm{b}}$ & $0.7^{\mathrm{b}}$ & $4^{b}$ \\
\hline $\begin{array}{c}{[\mathrm{Ch}] \mathrm{Cl}: \mathrm{Gly}: \mathrm{W}} \\
\left(10 \% \mathrm{D}_{2} \mathrm{O}\right)\end{array}$ & 2.72 & 5.10 & 3.18 & 5.71 & 9.65 \\
\hline $\begin{array}{c}{[\mathrm{Ch}] \mathrm{Cl}: \mathrm{Gly}: \mathrm{W}} \\
\left(90 \% \mathrm{D}_{2} \mathrm{O}\right)\end{array}$ & 78.0 & --- & 74.6 & --- & 173.5 \\
\hline
\end{tabular}


NMR $400 \mathrm{MHz}$ at $298 \mathrm{~K}$, the chemical shifts were: $\delta 3.25\left(\mathrm{~s}, 9 \mathrm{H}, \mathrm{H}_{\mathrm{d}}\right), 3.53-3.60(\mathrm{~m}, 2$

$\left.\mathrm{H}, \mathrm{H}_{\mathrm{c}}\right), 4.04\left(\mathrm{~s}, 2 \mathrm{H}, \mathrm{H}_{\mathrm{b}}\right), 4.53\left(\mathrm{~s}, 3 \mathrm{H}, \mathrm{H}_{\mathrm{f}}\right), 5.40-5.48\left(\mathrm{~m}, 1 \mathrm{H}, \mathrm{H}_{\mathrm{a}}\right), 6.12\left(\mathrm{~s}, 8 \mathrm{H}, \mathrm{H}_{\mathrm{e}}\right)$. The

${ }^{13} \mathrm{C}-\mathrm{NMR} 100 \mathrm{MHz}$ signals were: $\delta 54.0\left(\mathrm{t}, \mathrm{J}=3.7 \mathrm{~Hz}, \mathrm{C}_{\mathrm{d}}\right), 55.9\left(\mathrm{C}_{\mathrm{b}}\right), 67.7(\mathrm{t}, \mathrm{J}=2.7 \mathrm{~Hz}$,

$\left.\mathrm{C}_{\mathrm{c}}\right), 161.9\left(\mathrm{C}_{\mathrm{f}}\right)$. From the integration of each signal in ${ }^{1} \mathrm{H}$ spectrum, we have obtained the

242 following composition: choline chloride/urea/water in molar ratio 1:1.95:1.67 (water content: $10.5 \%$ wt.) with a standard uncertainty, $u(x)=0.05$.

244

(a)

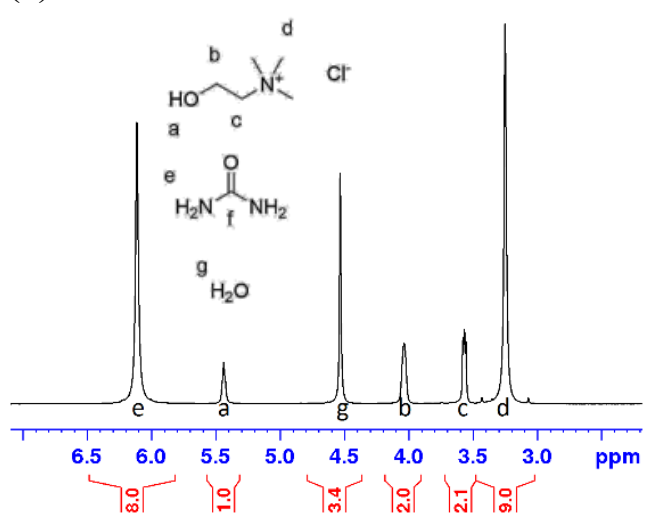

(b)

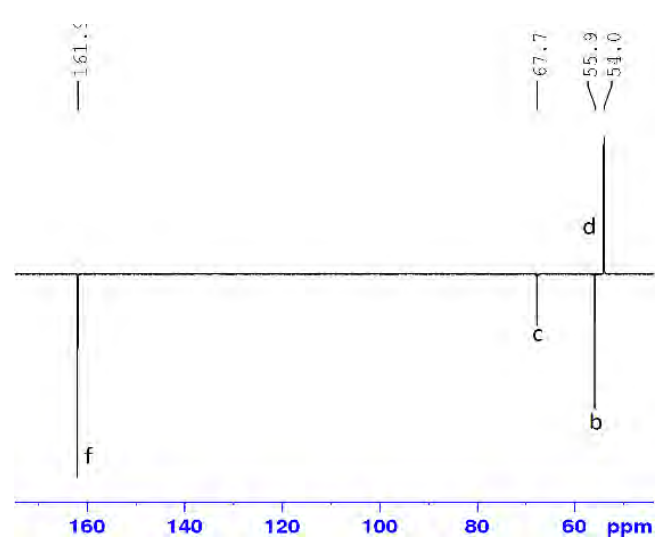

Figure 5. [Ch]Cl:U:W spectra at $298 \mathrm{~K}$ : (a) ${ }^{1} \mathrm{H}-\mathrm{NMR}$; (b) ${ }^{13} \mathrm{C}-\mathrm{NMR}$.

In the ${ }^{1} \mathrm{H}-\mathrm{NMR}$ for the ternary eutectic diluted with $10 \%$ or $90 \%$ deuterated water, $\mathrm{HDO}$, the $\mathrm{OH}-\mathrm{Ch}^{+}$signal appears with HDO (Fig. S4a). For the amine groups of the urea, the peak decreases in intensity by exchange with deuterium of the solvent. In the ${ }^{13} \mathrm{C}-\mathrm{NMR}$ (Fig. S4b), a drastic reduction of the urea carbonyl signal due to the exchange and coupling with deuterium atoms is observed. Also, the chemical shift signals changed in the following quantities: $\Delta \delta$ (neat - diluted) $=+0.3 \mathrm{C}_{\mathrm{b}},+0.3 \mathrm{C}_{\mathrm{c}},+0.1 \mathrm{C}_{\mathrm{d}},-0.8 \mathrm{C}_{\mathrm{f}}$. In the NOESY experiments with short time of mixing (Fig. 6a), only a negative peak of correlation indicating chemical exchange between $\mathrm{OH}-\mathrm{Ch}^{+}$and $\mathrm{W}$ is observed. Increasing $t_{\text {mix }}$ (Fig. $6 \mathrm{~b}$ and S5), an intermolecular positive nOe corresponding to the 
corresponding to choline methyl groups are detected. No U/W correlation is observed.

Fig. 6c shows a tentative drawing of the H-H interactions deduced from above results.

259

260

(a)

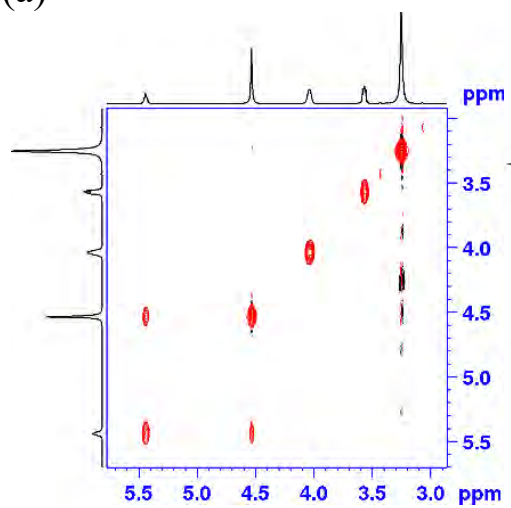

(b)

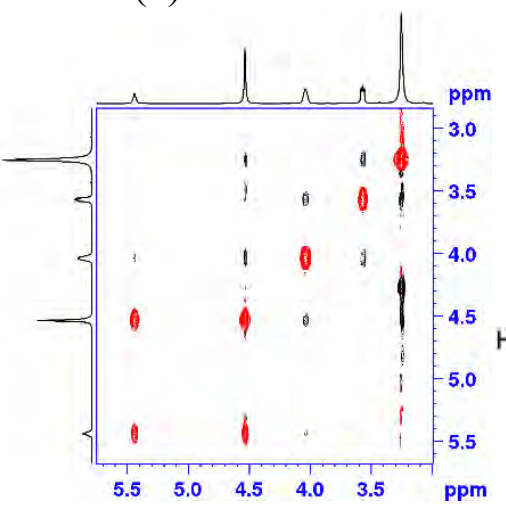

(c)

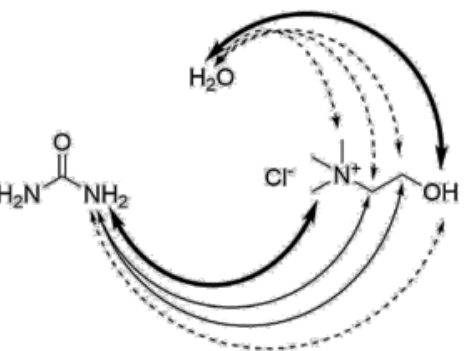

262 Fig. 6 NOESY spectra of [Ch]Cl:U:W at $298 \mathrm{~K}$ and at several mixing times: (a) $t_{m i x}=50$ ms, and (b) $t_{m i x}=800 \mathrm{~ms}$; (c) $\mathrm{H}-\mathrm{H}$ interactions representation. to the pure sample, with positive nOe crosspeaks among all present signals $\left(\mathrm{OH}-\mathrm{Ch}^{+}\right.$ signal appears with HDO), indicating that remains the close contact between the species. However, $90 \%$ diluted sample did not show any remarkable interaction apart those from intramolecular protons.

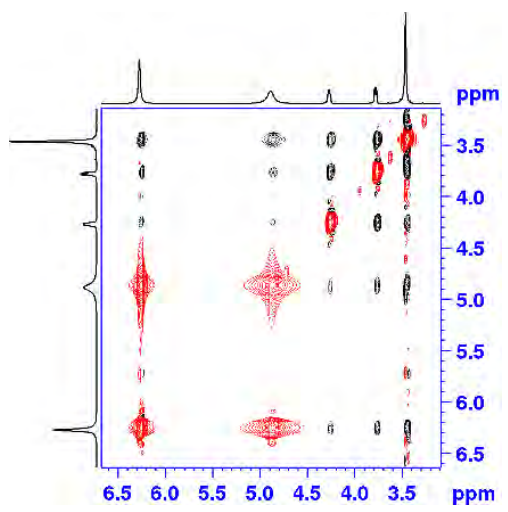
ms. 

different traces can be identified: $\mathrm{Ch}^{+}, \mathrm{OH}-\mathrm{Ch}^{+}, \mathrm{U}$, and W (Fig. 8a). Again, in order to calculate the self-diffusion coefficients, $D$, of the several species, we have fitted the logarithm of the spin echo attenuation versus the gradient using the eq. (1). The values obtained for $[\mathrm{Ch}] \mathrm{Cl}: \mathrm{U}: \mathrm{W}$ and those reported in the literature for the aqueous and nonaqueous eutectics $[25,26]$ are listed in Table 2 . The addition of water to the binary eutectic causes a difference of diffusivity between both type of hydrogens of the choline. Unlike the study previously published by D'Agostino et al. [26], we have not detected coalescence of the two peaks $\mathrm{OH}-\mathrm{Ch}^{+}$and W. Moreover, the $D$ coefficient of $\mathrm{U}$ is slightly lower than that of $\mathrm{OH}-\mathrm{Ch}^{+}$indicating a lower mobility due to a stronger interaction with the neighboring molecules. The $D$ coefficients calculated herein, except for the $\mathrm{OH}-\mathrm{Ch}^{+}$, are in good agreement with those. Our values are slightly higher but it is a logical result since the temperature is also slightly higher. Diffusion measurements with $10 \% \mathrm{D}_{2} \mathrm{O}$ diluted sample (Fig. $8 \mathrm{~b}$ ) gave very similar results in self-diffusion coefficients than the pure NADES, in the same order of magnitude. The unique value that increases the most is the one corresponding to the amine hydrogens from urea, possible solution system.

291

(a)

(b)

(c)
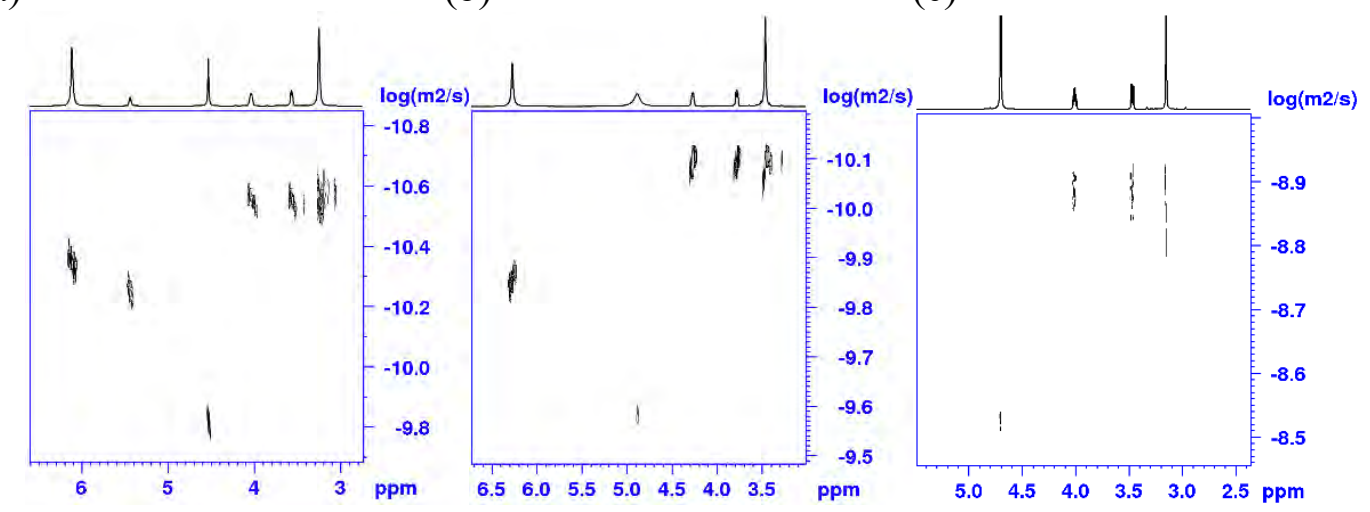
293

294

295

296

\begin{tabular}{|c|c|c|c|c|}
\hline DES & $\begin{array}{c}10^{11} D_{\mathrm{Ch}^{+}} \\
/ \mathrm{m}^{2} \cdot \mathrm{s}^{-1}\end{array}$ & $\begin{array}{c}10^{11} D_{\mathrm{OH}-\mathrm{Ch}^{+}} \\
/ \mathrm{m}^{2} \cdot \mathrm{s}^{-1}\end{array}$ & $\begin{array}{c}10^{11} \mathrm{D}_{\mathrm{NH}_{2}} \\
/ \mathrm{m}^{2} \cdot \mathrm{s}^{-1}\end{array}$ & $\begin{array}{c}10^{11} D_{\mathrm{H}_{2} \mathrm{O}} \\
/ \mathrm{m}^{2} \cdot \mathrm{s}^{-1}\end{array}$ \\
\hline$[\mathrm{Ch}] \mathrm{Cl}: \mathrm{U}$ & $0.35^{\mathrm{a}}$ & $0.35^{\mathrm{a}}$ & $0.66^{\mathrm{a}}$ & --- \\
\hline \multirow[t]{2}{*}[\mathrm{Ch}]{$\mathrm{Cl}: \mathrm{U}: \mathrm{W}$} & 2.50 & 4.49 & 4.07 & 10.2 \\
\hline & $2^{b}$ & $10^{\mathrm{b}}$ & $3^{b}$ & $10^{\mathrm{b}}$ \\
\hline$[\mathrm{Ch}] \mathrm{Cl}: \mathrm{U}: \mathrm{W}$ & 7.57 & --- & 13.2 & 23.9 \\
\hline$\left(10 \% \mathrm{D}_{2} \mathrm{O}\right)$ & & & & \\
\hline$[\mathrm{Ch}] \mathrm{Cl}: \mathrm{U}: \mathrm{W}$ & 82.35 & --- & 159.1 & 90.3 \\
\hline$\left(90 \% \mathrm{D}_{2} \mathrm{O}\right)$ & & & & \\
\hline \multicolumn{5}{|c|}{ D'Agostino et al. [25]; ${ }^{b}$ D'Agostino et al .[26], $T=293 \mathrm{~K}$. } \\
\hline
\end{tabular}

297

298

299

300

301

302

303

304

305

306 and (c) $90 \%$ of $\mathrm{D}_{2} \mathrm{O}$. aqueous and aqueous DES with urea. $\left.\mathrm{H}, \mathrm{H}_{\mathrm{c}}, \mathrm{H}_{\mathrm{f}}\right), 4.12\left(\mathrm{~s}, 2 \mathrm{H}, \mathrm{H}_{\mathrm{b}}\right), 4.56\left(\mathrm{~s}, 2 \mathrm{H}, \mathrm{H}_{\mathrm{g}}\right), 5.10\left(\mathrm{~s}, 4 \mathrm{H}, \mathrm{H}_{\mathrm{e}}\right), 5.44-5.55\left(\mathrm{~m}, 1 \mathrm{H}, \mathrm{H}_{\mathrm{a}}\right)$. In the ${ }^{13} \mathrm{C}-\mathrm{NMR}$ spectrum (Fig. 9b), the signals are the expected: $\delta 54.1(\mathrm{t}, \mathrm{J}=4.0 \mathrm{~Hz}$, calculated water content is $8.5 \%$ wt.

Figure 8. DOSY experiments of [Ch]Cl:U:W at $298 \mathrm{~K}$. (a) neat eutectic; (b) $10 \%$ of $\mathrm{D}_{2} \mathrm{O}$;

Table 2. The self-diffusion coefficients, $D$, at $298 \mathrm{~K}$ of the several species in the non-

Figure 9a shows the ${ }^{1} \mathrm{H}-\mathrm{NMR}$ spectrum of this DES. We can see that the peaks of the $\mathrm{CH}_{2}-\mathrm{N}^{+}$of the choline and the aliphatic hydrogens of the ethylene glycol are overlapped. The rest are separated and can be identified: $\delta 3.38\left(\mathrm{~s}, 9 \mathrm{H}, \mathrm{H}_{\mathrm{d}}\right), 3.70(\mathrm{~s}, 10$ $\left.\mathrm{C}_{\mathrm{d}}\right), 56.1\left(\mathrm{C}_{\mathrm{b}}\right), 63.3\left(\mathrm{C}_{\mathrm{f}}\right), 67.7\left(\mathrm{t}, \mathrm{J}=3.0 \mathrm{~Hz}, \mathrm{C}_{\mathrm{c}}\right)$. The molar ratio of the several components, choline chloride/ethylene glycol/water, is: 1:1.89:1.33 $(u(x)=0.05)$. The

With $10 \%$ dilution of $\mathrm{D}_{2} \mathrm{O}$, a slight displacement of the ethylene signal respect to that of the $\mathrm{CH}_{2}-\mathrm{N}^{+}$is produced (Fig. S6a). Also, all mobile hydrogens $\left(\mathrm{OH}-\mathrm{Ch}^{+}, \mathrm{OH}-\right.$ 

overlapped appear full separated and the mobile hydrogens coalesce to the HDO signal.

311 Respect to the ${ }^{13} \mathrm{C}$, the signals of the carbons attached to the oxygen are the most changing 312 (Fig. S6b): $\Delta \delta$ (neat - diluted) $=-0.3 \mathrm{C}_{\mathrm{b}},-0.0 \mathrm{C}_{\mathrm{d}},-0.1 \mathrm{C}_{\mathrm{c}},-0.5 \mathrm{C}_{\mathrm{f}}$.

313 (a)

314

315 (b)

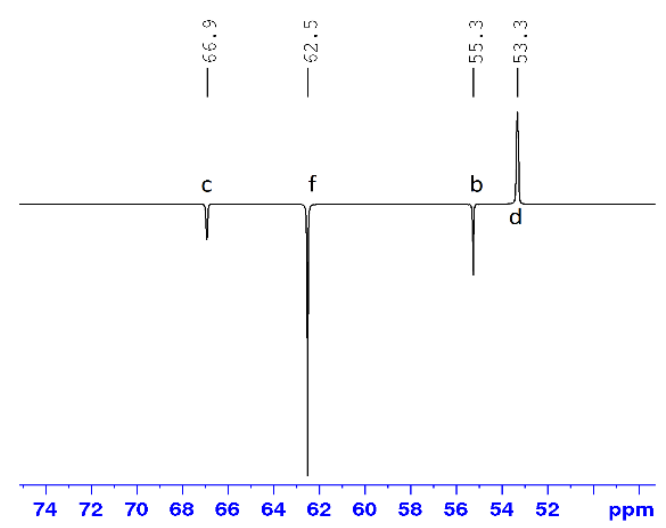

Figure 9. [Ch]Cl:EG:W spectra at $298 \mathrm{~K}$ : (a) ${ }^{1} \mathrm{H}-\mathrm{NMR}$ (b) ${ }^{13} \mathrm{C}-\mathrm{NMR}$.

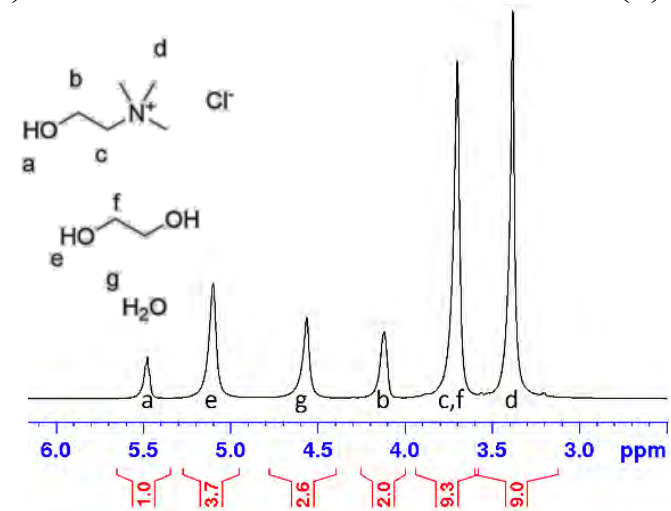

\footnotetext{
Figure 9. [Ch]Cl:EG:W spectra at $298 \mathrm{~K}:$ (a) ${ }^{\mathrm{l}} \mathrm{H}-\mathrm{NMR}$ (b) ${ }^{13} \mathrm{C}-\mathrm{NMR}$.
}

The NOESY spectrum at short $t_{m i x}$ (Fig. 10a) exhibits only exchange signals between the water and the hydroxyls of both choline and ethylene glycol; these latter are more intense. Increasing $t_{\text {mix }}$ (Fig. S7), in addition to the exchange signals, we obtain positive nOes corresponding to both the intramolecular signals of the choline and the strong EG/W interaction. For $t_{\text {mix }}>500 \mathrm{~ms}$ (Fig. 10b), crossing peaks between all ${ }^{1} \mathrm{H}$ signals are observed. The intensity of hydrogen interactions is represented in Fig. 10c. To emphasize that contrary to the other studied eutectics, the donor specie in this mixture (ethylene glycol) is the one that presents stronger interactions, especially with water. NOESY spectra for the diluted samples did not afford any significant information, mainly due to the coalescence of the hydroxyl signals with HDO.

Fig. 11 shows the measured DOSY experiment for this DES. The self-diffusion constants calculated with eq. 1 (Table 3 ) show a clearly difference of mobility between 
328 the several species, to except $\mathrm{OH}-\mathrm{EG}$ and $\mathrm{W}$ which have similar values. This result is in 329 accordance with the above conclusions and with those previously published [26]. From 330 the overlapped signal for $\mathrm{CH}_{2}-\mathrm{N}^{+}$and $\mathrm{EG}$, we have obtained an apparent coefficient, $331 D_{a p p}=6.83 \cdot 10^{-11} \mathrm{~m}^{2} / \mathrm{s}$. Taking into account the calculated value of $D_{\mathrm{Ch}^{+}}$in this DES 332 (Table 3 ), we can deduce that $D_{\mathrm{EG}}$ will be significantly higher. Therefore, it can be 333 concluded that a weak eutectic structure is established. As for the diluted samples the

334 aliphatic hydrogens appear separated, it is possible to calculate the self-diffusion constant 335 for each specie, however, all hydroxyl protons collapse to HDO signal, so no information 336 can be obtained from them.

337

(a)

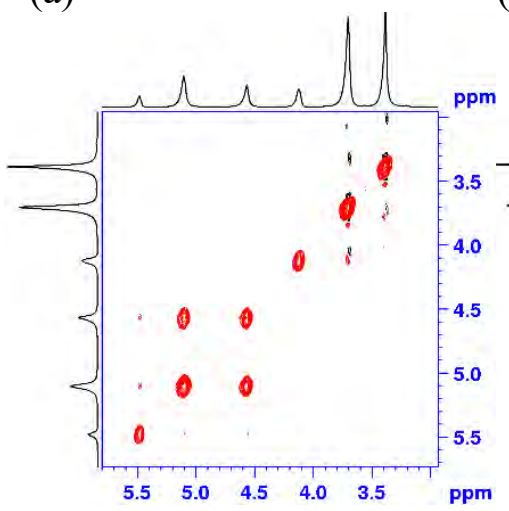

(b)

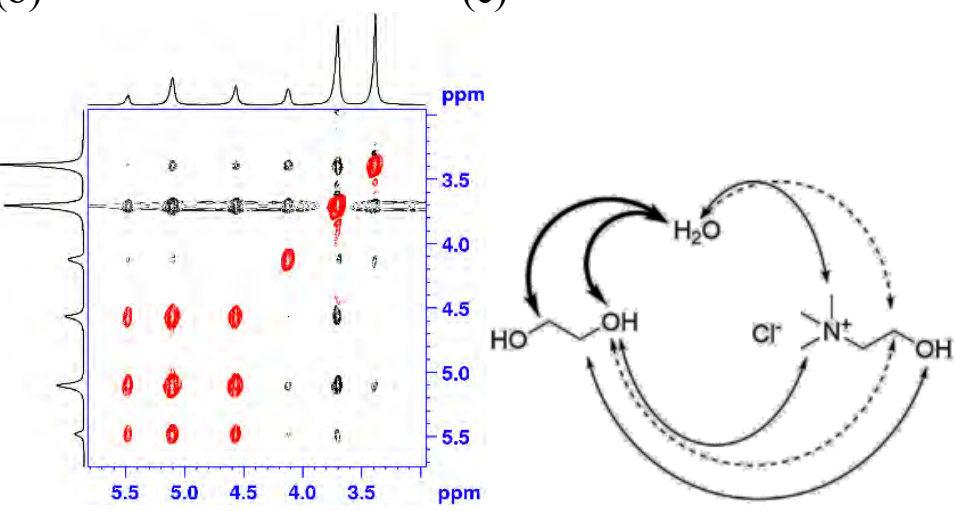

Figure 10. NOESY spectra of [Ch]Cl:EG:W at $298 \mathrm{~K}$ and at several mixing times: (a) $t_{m i x}=50 \mathrm{~ms}$, and (b) $t_{m i x}=800 \mathrm{~ms}$; (c) H-H interactions representation.

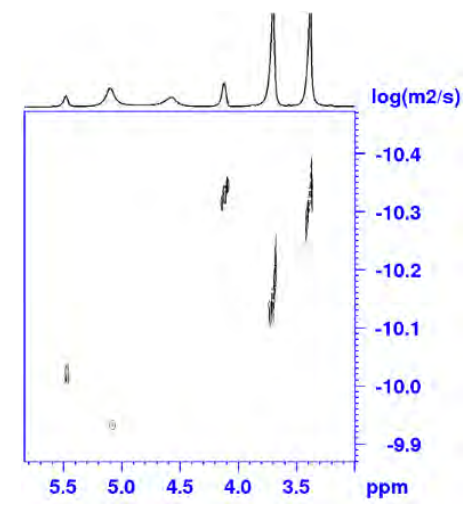

Figure 11. DOSY experiment of [Ch]Cl:EG:W at $298 \mathrm{~K}$. 
Table 3. The self-diffusion coefficients, $D$, at $298 \mathrm{~K}$ of the several species in the nonaqueous and aqueous DES with ethylene glycol.

\begin{tabular}{cccccc}
\hline DES & $\begin{array}{c}10^{11} D_{\mathrm{Ch}^{+}} \\
/ \mathrm{m}^{2} \cdot \mathrm{s}^{-1}\end{array}$ & $\begin{array}{c}10^{11} D_{\mathrm{OH}-\mathrm{Ch}^{+}} / \mathrm{m}^{2} \cdot \mathrm{s}^{-1} \\
10^{11} D_{\mathrm{EG}} \\
/ \mathrm{m}^{2} \cdot \mathrm{s}^{-1}\end{array}$ & $\begin{array}{c}10^{11} D_{\mathrm{OH}-\mathrm{EG}} \\
/ \mathrm{m}^{2} \cdot \mathrm{s}^{-1}\end{array}$ & $\begin{array}{c}10^{11} D_{\mathrm{H}_{2} \mathrm{O}} \\
/ \mathrm{m}^{2} \cdot \mathrm{s}^{-1}\end{array}$ \\
\hline$[\mathrm{Ch}]$ Cl:Gly & $2.62^{\mathrm{a}}$ & $2.62^{\mathrm{a}}$ & $4.77^{\mathrm{a}}$ & $4.77^{\mathrm{a}}$ & --- \\
{$[\mathrm{Ch}] \mathrm{Cl}:$ Gly:W } & 4.56 & 9.00 & --- & 10.7 & 10.3 \\
& $4^{\mathrm{b}}$ & $7^{\mathrm{b}}$ & $5.8^{\mathrm{b}}$ & $9^{\mathrm{b}}$ & $9^{\mathrm{b}}$ \\
{$[\mathrm{Ch}] \mathrm{Cl}: \mathrm{Gly}: \mathrm{W}$} & 8.45 & --- & 12.6 & -- & $25.9^{\mathrm{c}}$ \\
$\left(10 \% \mathrm{D}_{2} \mathrm{O}\right)$ & & & & & \\
{$[\mathrm{Ch}] \mathrm{Cl}: \mathrm{Gly}: \mathrm{W}$} & 70.5 & --- & 85.4 & --- & 168.6 \\
$\left(90 \% \mathrm{D}_{2} \mathrm{O}\right)$ & & & & &
\end{tabular}

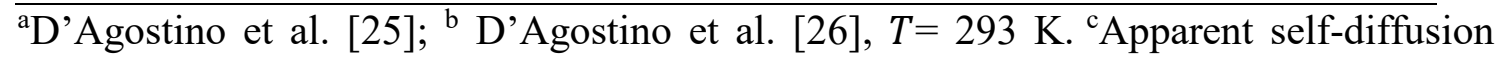
constant.

\section{Conclusions}

This paper has investigated the structure of three aqueous eutectics from several NMR experiments. The purpose of the current study was to assess the interactions between the species within the liquid as well as the role of the water in the mixtures. Also, we have calculated self-diffusion coefficients from DOSY spectra.

The composition of the studied eutectics has been: choline chloride, urea or glycerol or ethylene glycol, and water with a water content less to $10.5 \% \mathrm{wt}$. The results of this research support the idea that a supramolecular structure in these eutectic fluids is presented. For the eutectic with urea, the stronger interactions appear between the hydroxyl protons of the choline and the water followed by those between the methyl groups of the choline and the urea. No correlation urea/water is observed. For the second eutectic, interactions among all species are detected. Both the aliphatic and hydroxyl 
hydrogens of the glycerol exhibit a significant correlation with the methyl groups of the choline. The glycerol/water shows the weakest signal. Contrary to the previous mixtures, the strongest interactions in the eutectic formed by ethylene glycol are those established between the donor component and water. This eutectic has the feeblest structure. Finally, we have found that these ternary solvents still retain the eutectic character when are diluted at $10 \% \mathrm{wt}$.

\section{Supplementary data}

Supplementary data to this article can be found in version online.

\section{Acknowledgements}

This research was supported by Gobierno de Aragón (Grant E31_17R), Fondo de

Desarrollo Regional "Construyendo Europa desde Aragón”. The authors would like to thank the financial assistance.

\section{References}

[1] M. Vert, Y. Doi, K. Hellwich, M. Hess, P. Hodge, P. Kubisa, M. Rinaudo, F. Recommendations 2012 )*, 84 (2012) 377-410.

[2] F.G. Calvo-Flores, M.J. Monteagudo-Arrebola, J.A. Dobado, J. Isac-García, Green and Bio-Based Solvents, Top. Curr. Chem. 376 (2018) 1-40. doi:10.1007/s41061-018-0191-6.

[3] C.J. Clarke, W.C. Tu, O. Levers, A. Bröhl, J.P. Hallett, Green and Sustainable Solvents in Chemical Processes, Chem. Rev. 118 (2018) 747-800. doi:10.1021/acs.chemrev.7b00571. 
[4] M. Francisco, A. Van Den Bruinhorst, M.C. Kroon, Low-transition-temperature mixtures (LTTMs): A new generation of designer solvents, Angew. Chemie - Int. Ed. 52 (2013) 3074-3085. doi:10.1002/anie.201207548.

[5] E. Durand, J. Lecomte, P. Villeneuve, From green chemistry to nature: The versatile role of low transition temperature mixtures, Biochimie. 120 (2016) 119123. doi:10.1016/j.biochi.2015.09.019.

[6] B. Kudłak, K. Owczarek, J. Namieśnik, Selected issues related to the toxicity of ionic liquids and deep eutectic solvents - a review, Environ. Sci. Pollut. Res. 22 (2015) 11975-11992. doi:10.1007/s11356-015-4794-y.

[7] S.P.F. Costa, A.M.O. Azevedo, P.C.A.G. Pinto, M.L.M.F.S. Saraiva, Environmental Impact of Ionic Liquids: Recent Advances in (Eco)toxicology and (Bio)degradability, ChemSusChem. 10 (2017) 2321-2347. doi:10.1002/cssc.201700261.

[8] A.P. Abbott, D. Boothby, G. Capper, D.L. Davies, R.K. Rasheed, Deep Eutectic Solvents formed between choline chloride and carboxylic acids: Versatile alternatives to ionic liquids, J. Am. Chem. Soc. 126 (2004) 9142-9147. doi:10.1021/ja048266j.

[9] F. Pena-Pereira, A. Kloskowski, J. Namieśnik, Perspectives on the replacement of harmful organic solvents in analytical methodologies: A framework toward the implementation of a generation of eco-friendly alternatives, Green Chem. 17 (2015) 3687-3705. doi:10.1039/c5gc00611b.

[10] M. Espino, M. de los Ángeles Fernández, F.J.V. Gomez, M.F. Silva, Natural designer solvents for greening analytical chemistry, TrAC - Trends Anal. Chem. 
76 (2016) 126-136. doi:10.1016/j.trac.2015.11.006.

405

406

407

408

409

410

411

412

413

414

415

416

417

418

419

420

421

422

423

424

425

426

[11] D.J.G.P. Van Osch, L.F. Zubeir, A. Van Den Bruinhorst, M.A.A. Rocha, M.C. Kroon, Hydrophobic Deep Eutectic Solvents : Water- Immiscible Extractants, (2015) 1-36. doi:10.1039/C5GC01451D.

[12] B.D. Ribeiro, C. Florindo, L.C. Iff, M.A.Z. Coelho, I.M. Marrucho, Mentholbased eutectic mixtures: Hydrophobic low viscosity solvents, ACS Sustain. Chem. Eng. 3 (2015) 2469-2477. doi:10.1021/acssuschemeng.5b00532.

[13] M.A.R. Martins, E.A. Crespo, P.V.A. Pontes, L.P. Silva, M. Bülow, G.J. Maximo, E.A.C. Batista, C. Held, S.P. Pinho, J.A.P. Coutinho, Tunable Hydrophobic Eutectic Solvents Based on Terpenes and Monocarboxylic Acids, ACS Sustain. Chem. Eng. 6 (2018) 8836-8846.

doi:10.1021/acssuschemeng.8b01203.

[14] Y.H. Choi, J. van Spronsen, Y. Dai, M. Verberne, F. Hollmann, I.W.C.E. Arends, G.-J. Witkamp, R. Verpoorte, Are Natural Deep Eutectic Solvents the Missing Link in Understanding Cellular Metabolism and Physiology?, Plant Physiol. 156 (2011) 1701-1705. doi:10.1104/pp.111.178426.

[15] I.M. Aroso, R. Craveiro, Â. Rocha, M. Dionísio, S. Barreiros, R.L. Reis, A. Paiva, A.R.C. Duarte, Design of controlled release systems for THEDESTherapeutic deep eutectic solvents, using supercritical fluid technology, Int. J. Pharm. 492 (2015) 73-79. doi:10.1016/j.ijpharm.2015.06.038.

[16] Y. Dai, J. van Spronsen, G.J. Witkamp, R. Verpoorte, Y.H. Choi, Natural deep eutectic solvents as new potential media for green technology, Anal. Chim. Acta. 766 (2013) 61-68. doi:10.1016/j.aca.2012.12.019. 
[17] M. Hayyan, M.A. Hashim, A. Hayyan, M.A. Al-Saadi, I.M. AlNashef, M.E.S. Mirghani, O.K. Saheed, Are deep eutectic solvents benign or toxic?, Chemosphere. 90 (2013) 2193-2195. doi:10.1016/j.chemosphere.2012.11.004.

[18] B. Zhao, P. Xu, F. Yang, H. Wu, M. Zong, W. Lou, Biocompatible Deep Eutectic Solvents Based on Choline Chloride: Characterization and Application to the Extraction of Rutin from Sophora japonica, (2015). doi:10.1021/acssuschemeng.5b00619.

[19] P. De Morais, F. Gonçalves, J.A.P. Coutinho, S.P.M. Ventura, Ecotoxicity of Cholinium-Based Deep Eutectic Solvents, ACS Sustain. Chem. Eng. 3 (2015) 3398-3404. doi:10.1021/acssuschemeng.5b01124.

[20] K.S. Egorova, V.P. Ananikov, Fundamental importance of ionic interactions in the liquid phase: A review of recent studies of ionic liquids in biomedical and pharmaceutical applications, J. Mol. Liq. 272 (2018) 271-300. doi:10.1016/j.molliq.2018.09.025.

[21] Y.P. Mbous, M. Hayyan, W.F. Wong, C.Y. Looi, M.A. Hashim, Unraveling the cytotoxicity and metabolic pathways of binary natural deep eutectic solvent systems, Sci. Rep. 7 (2017) 1-14. doi:10.1038/srep41257.

[22] H. Shekaari, M.T. Zafarani-Moattar, B. Mohammadi, Thermophysical characterization of aqueous deep eutectic solvent (choline chloride/urea) solutions in full ranges of concentration at $\mathrm{T}=(293.15-323.15) \mathrm{K}$, J. Mol. Liq. 243 (2017) 451-461. doi:10.1016/j.molliq.2017.08.051.

[23] D. Lapeña, L. Lomba, M. Artal, C. Lafuente, B. Giner, The NADES glyceline as a potential Green Solvent: A comprehensive study of its thermophysical 
properties and effect of water inclusion, J. Chem. Thermodyn. 128 (2019) 164 172. doi:10.1016/j.jct.2018.07.031.

452

453

454

455

456

457

458

459

460

461

462

463

464

465

466

467

468

469

470

471

472

[24] Y. Chen, D. Yu, W. Chen, L. Fu, T. Mu, Water absorption by deep eutectic solvents, Phys. Chem. Chem. Phys. 21 (2019) 2601-2610. doi:10.1039/C8CP07383J.

[25] C. D'Agostino, R.C. Harris, A.P. Abbott, L.F. Gladden, M.D. Mantle, Molecular motion and ion diffusion in choline chloride based deep eutectic solvents studied by1H pulsed field gradient NMR spectroscopy, Phys. Chem. Chem. Phys. 13 (2011) 21383-21391. doi:10.1039/c1cp22554e.

[26] C. D’Agostino, L.F. Gladden, M.D. Mantle, A.P. Abbott, E.I. Ahmed, A.Y.M. Al-Murshedi, R.C. Harris, Molecular and ionic diffusion in aqueous-deep eutectic solvent mixtures: Probing inter-molecular interactions using PFG NMR, Phys. Chem. Chem. Phys. 17 (2015) 15297-15304. doi:10.1039/c5cp01493j.

[27] E. Posada, N. López-Salas, R.J. Jiménez Riobóo, M.L. Ferrer, M.C. Gutiérrez, F. del Monte, Reline aqueous solutions behaving as liquid mixtures of H-bonded co-solvents: microphase segregation and formation of co-continuous structures as indicated by Brillouin and 1 H NMR spectroscopies, Phys. Chem. Chem. Phys. 19 (2017) 17103-17110. doi:10.1039/C7CP02180A.

[28] O.S. Hammond, D.T. Bowron, K.J. Edler, The Effect of Water upon Deep Eutectic Solvent Nanostructure: An Unusual Transition from Ionic Mixture to Aqueous Solution, Angew. Chemie - Int. Ed. 56 (2017) 9782-9785. doi:10.1002/anie.201702486.

[29] D. Shah, F.S. Mjalli, Effect of water on the thermo-physical properties of Reline: 
An experimental and molecular simulation based approach, Phys. Chem. Chem. Phys. 16 (2014) 23900-23907. doi:10.1039/c4cp02600d.

[30] T. Zhekenov, N. Toksanbayev, Z. Kazakbayeva, D. Shah, F.S. Mjalli, Formation of type III Deep Eutectic Solvents and effect of water on their intermolecular interactions, Fluid Phase Equilib. 441 (2017) 43-48. doi:10.1016/j.fluid.2017.01.022.

[31] R. Stefanovic, M. Ludwig, G.B. Webber, R. Atkin, A.J. Page, Nanostructure, hydrogen bonding and rheology in choline chloride deep eutectic solvents as a function of the hydrogen bond donor, Phys. Chem. Chem. Phys. 19 (2017) 32973306. doi:10.1039/C6CP07932F.

[32] M. Francisco, A. Van Den Bruinhorst, M.C. Kroon, New natural and renewable low transition temperature mixtures (LTTMs): Screening as solvents for lignocellulosic biomass processing, Green Chem. 14 (2012) 2153-2157. doi:10.1039/c2gc35660k.

[33] C. Florindo, F.S. Oliveira, L.P.N. Rebelo, A.M. Fernandes, I.M. Marrucho, Insights into the synthesis and properties of deep eutectic solvents based on cholinium chloride and carboxylic acids, ACS Sustain. Chem. Eng. 2 (2014) 2416-2425. doi:10.1021/sc500439w.

[34] J. Andanson, M. Traïkia, P. Husson, Ionic association and interactions in aqueous methylsulfate alkyl-imidazolium-based ionic liquids, J. Chem. Thermodyn. 77 (2014) 214-221. doi:10.1016/j.jct.2014.01.031. 


\section{SUPLEMENTARY MATERIAL}

\section{NMR study of choline chloride-based deep eutectic}

\section{solvents}

Ignacio Delso ${ }^{\mathrm{a}}$, Carlos Lafuente ${ }^{\mathrm{b}}$, José Muñoz-Embid ${ }^{\mathrm{b}}$, Manuela Artal $^{\mathrm{b}}$,*

a Instituto de Síntesis Química y Catálisis Homogénea (ISQCH) and Servicio de

Resonancia Magnética Nuclear, Centro de Química y Materiales de

Aragón (CEQMA), Universidad de Zaragoza-CSIC, Spain

${ }^{\mathrm{b}}$ Departamento de Química Física, Universidad de Zaragoza, Zaragoza, Spain 
Table S1. Characteristics of the studied DESs. Nomenclature used in this paper, composition, molar ratio, and calculated water content (mass percentage).

\begin{tabular}{cccccc}
\hline $\begin{array}{c}\text { DES } \\
\text { abbreviation }\end{array}$ & $\begin{array}{c}\text { Component } \\
\text { 1(HBA) }\end{array}$ & $\begin{array}{c}\text { Component } \\
\text { 2(HBD) }\end{array}$ & $\begin{array}{c}\text { Component } \\
3\end{array}$ & $\begin{array}{c}\text { Molar } \\
\text { ratio }^{\mathrm{a}}\end{array}$ & $\begin{array}{c}\text { Water content } \\
/(\mathrm{wt} \%)\end{array}$ \\
\hline$[\mathrm{Ch}] \mathrm{Cl}: \mathrm{Gly}: \mathrm{W}$ & $\begin{array}{c}\text { Choline } \\
\text { chloride }\end{array}$ & Glycerol & Water & $1: 1.96: 0.97$ & 5.3 \\
{$[\mathrm{Ch}] \mathrm{Cl}: \mathrm{U}: \mathrm{W}$} & $\begin{array}{c}\text { Choline } \\
\text { chloride }\end{array}$ & Urea & Water & $1: 1.95: 1.67$ & 10.5 \\
{$[\mathrm{Ch}] \mathrm{Cl}: \mathrm{EG}: \mathrm{W}$} & $\begin{array}{c}\text { Choline } \\
\text { chloride }\end{array}$ & $\begin{array}{c}\text { Ethylene } \\
\text { Glycol }\end{array}$ & Water & $1: 1.89: 1.33$ & 8.5 \\
\hline
\end{tabular}

$\overline{{ }^{a}}$ NMR characterization; standard uncertainty, $u(x)=0.05$. The compositions are in agreement with those calculated from the quantities weighed in and from Karl-Fischer method. 


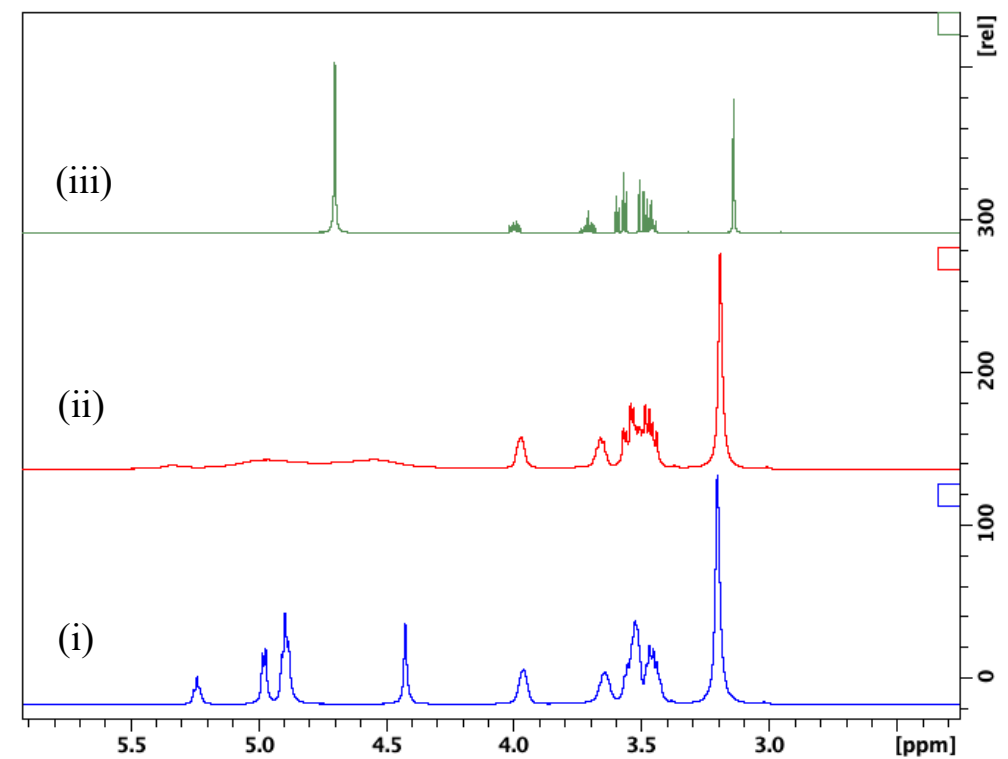

Figure S1a. ${ }^{1} \mathrm{H}-\mathrm{NMR} 400 \mathrm{MHz}$ spectra of [Ch]Cl:Gly:W at $298 \mathrm{~K}$. i) neat eutectic; ii) 10 $\% \mathrm{D}_{2} \mathrm{O}$; iii) $90 \% \mathrm{D}_{2} \mathrm{O}$.

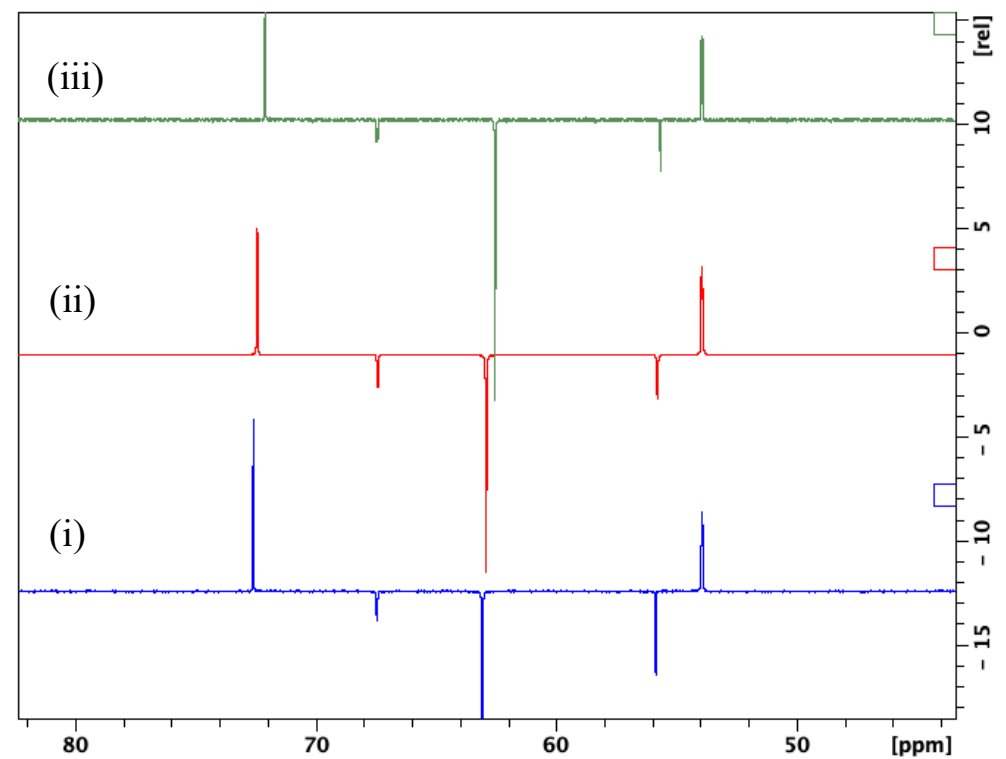

Figure S1b. ${ }^{13} \mathrm{C}$ spectra of $[\mathrm{Ch}] \mathrm{Cl}: \mathrm{Gly}: \mathrm{W}$ at $298 \mathrm{~K}$. i) neat eutectic; ii) $10 \% \mathrm{D}_{2} \mathrm{O}$; iii) 90 $\% \mathrm{D}_{2} \mathrm{O}$. 

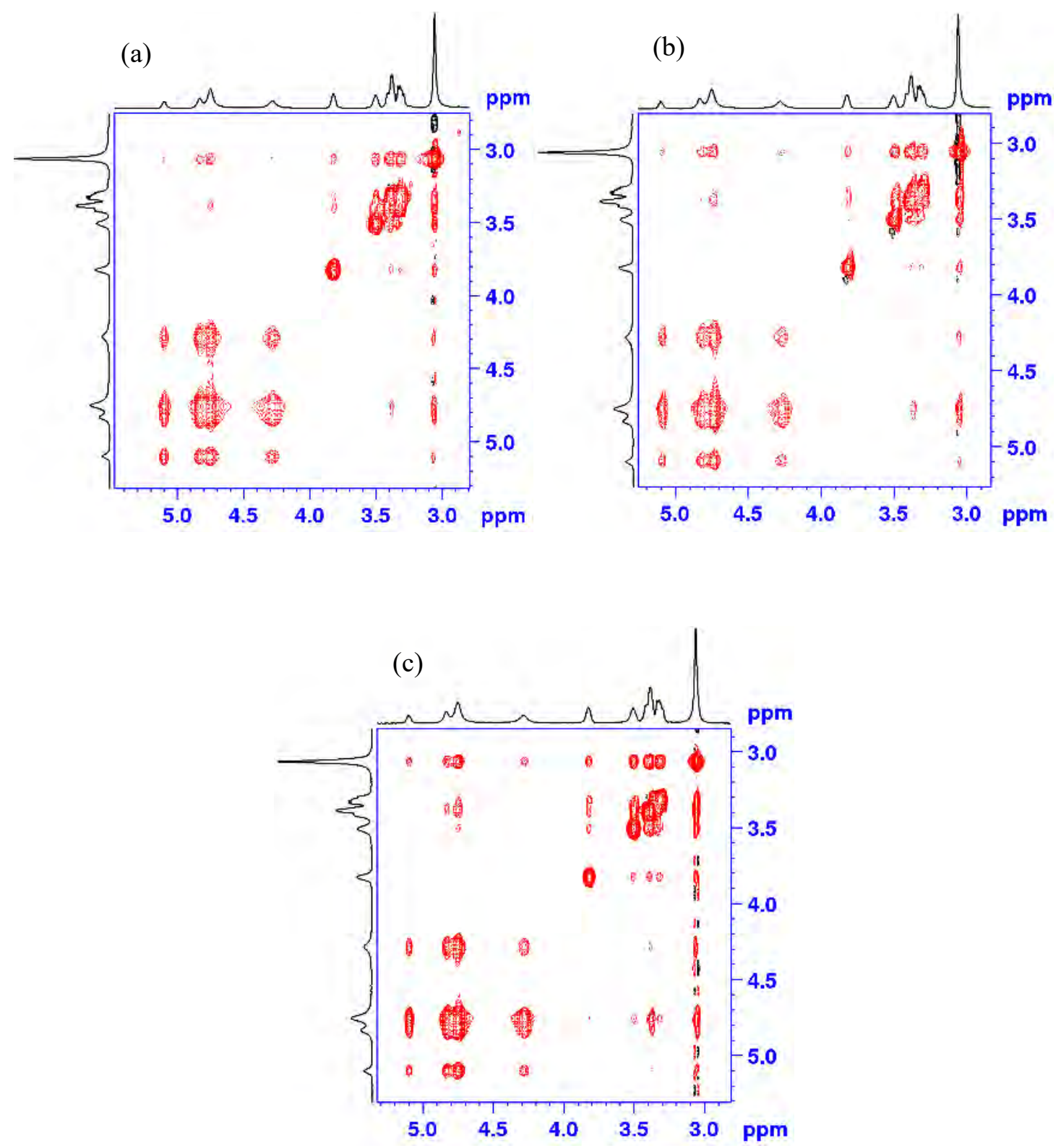

Figure S2. NOESY spectra of [Ch]Cl:Gly:W at $298 \mathrm{~K}$ and at several mixing times: (a) $t_{m i x}=200 \mathrm{~ms}$; (b) $t_{m i x}=500 \mathrm{~ms}$; (c) $t_{m i x}=800 \mathrm{~ms}$, spectrum made six months after the previous. 


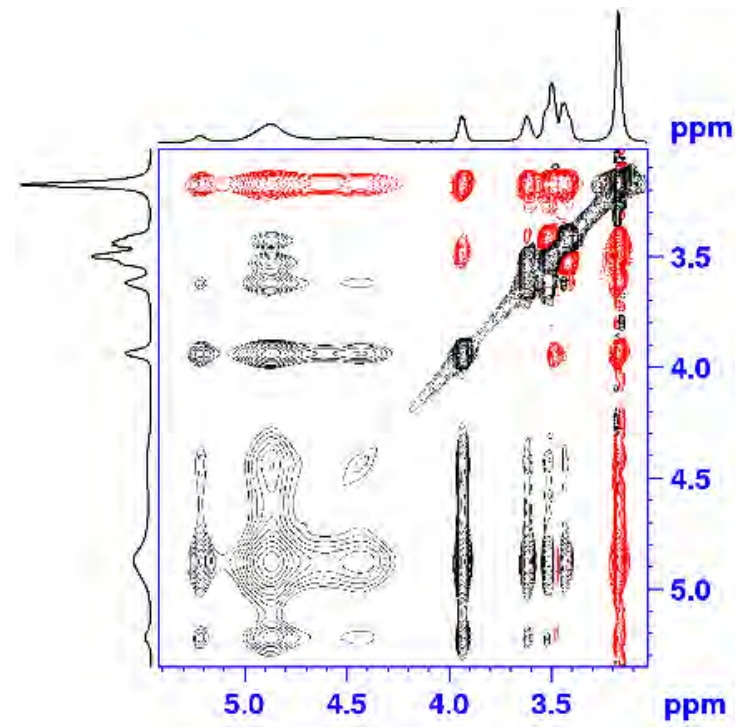

Figure S3. ROESY spectra of [Ch]Cl:Gly:W at $298 \mathrm{~K}$. 


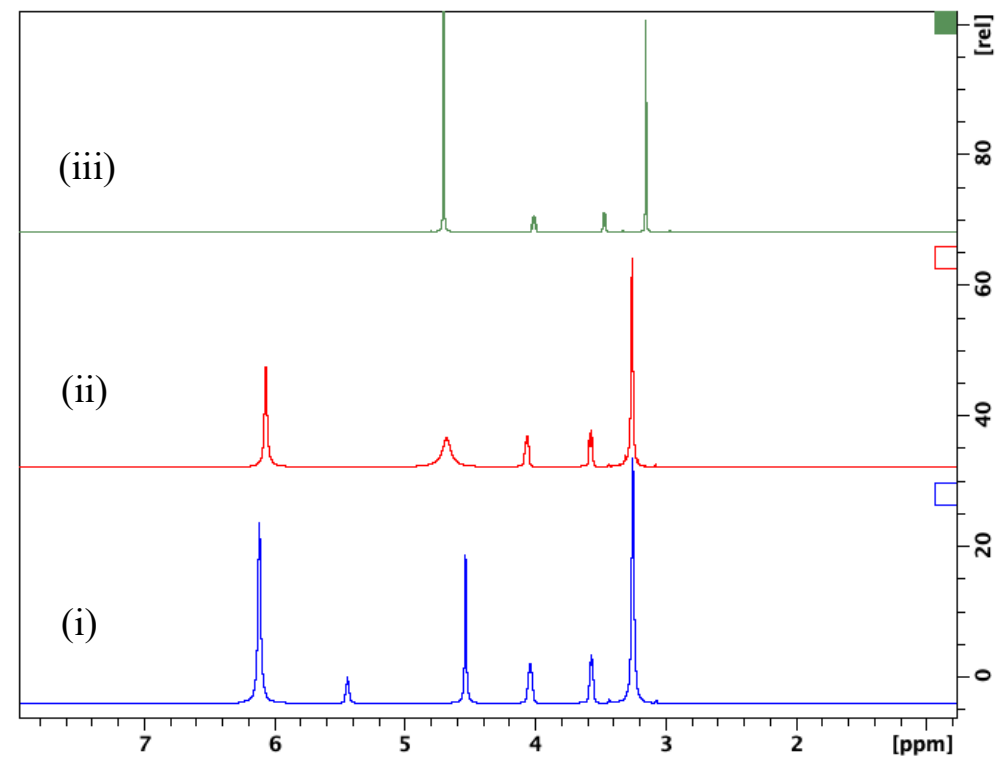

Figure S4a. ${ }^{1} \mathrm{H}-\mathrm{NMR} 400 \mathrm{MHz}$ spectra of $[\mathrm{Ch}] \mathrm{Cl}: \mathrm{U}: \mathrm{W}$ at $298 \mathrm{~K}$. i) neat eutectic; ii) 10 $\% \mathrm{D}_{2} \mathrm{O}$; iii) $90 \% \mathrm{D}_{2} \mathrm{O}$.

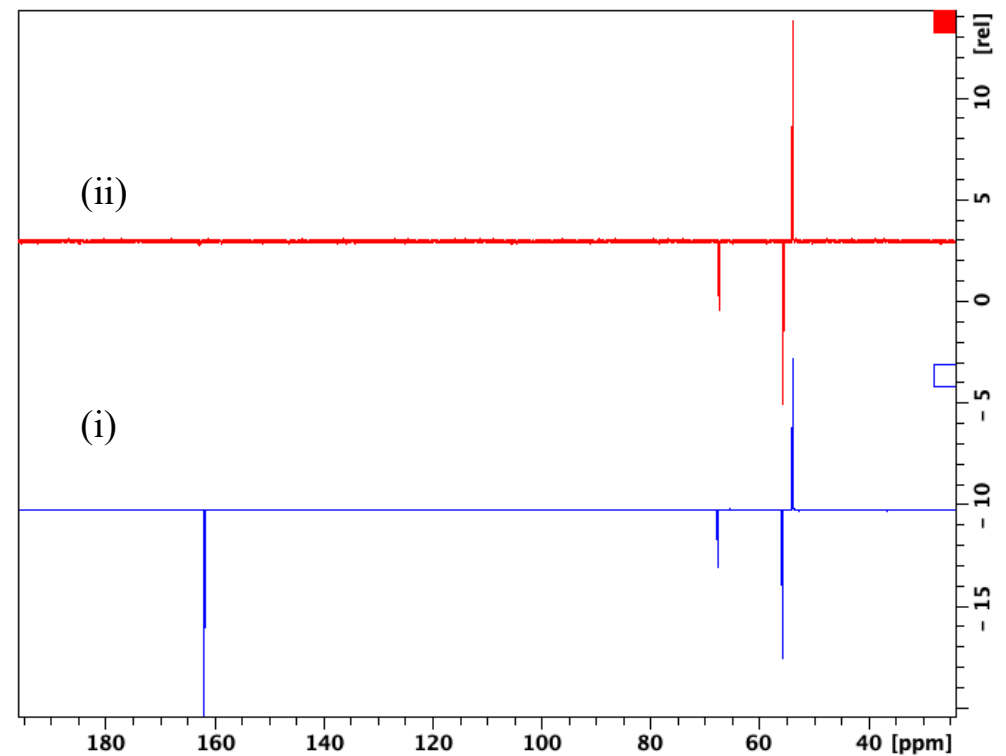

Figure S4b. ${ }^{13} \mathrm{C}$ spectra of $[\mathrm{Ch}] \mathrm{Cl}: \mathrm{U}: \mathrm{W}$ at $298 \mathrm{~K}$. i) neat eutectic; ii) $90 \% \mathrm{D}_{2} \mathrm{O}$. 

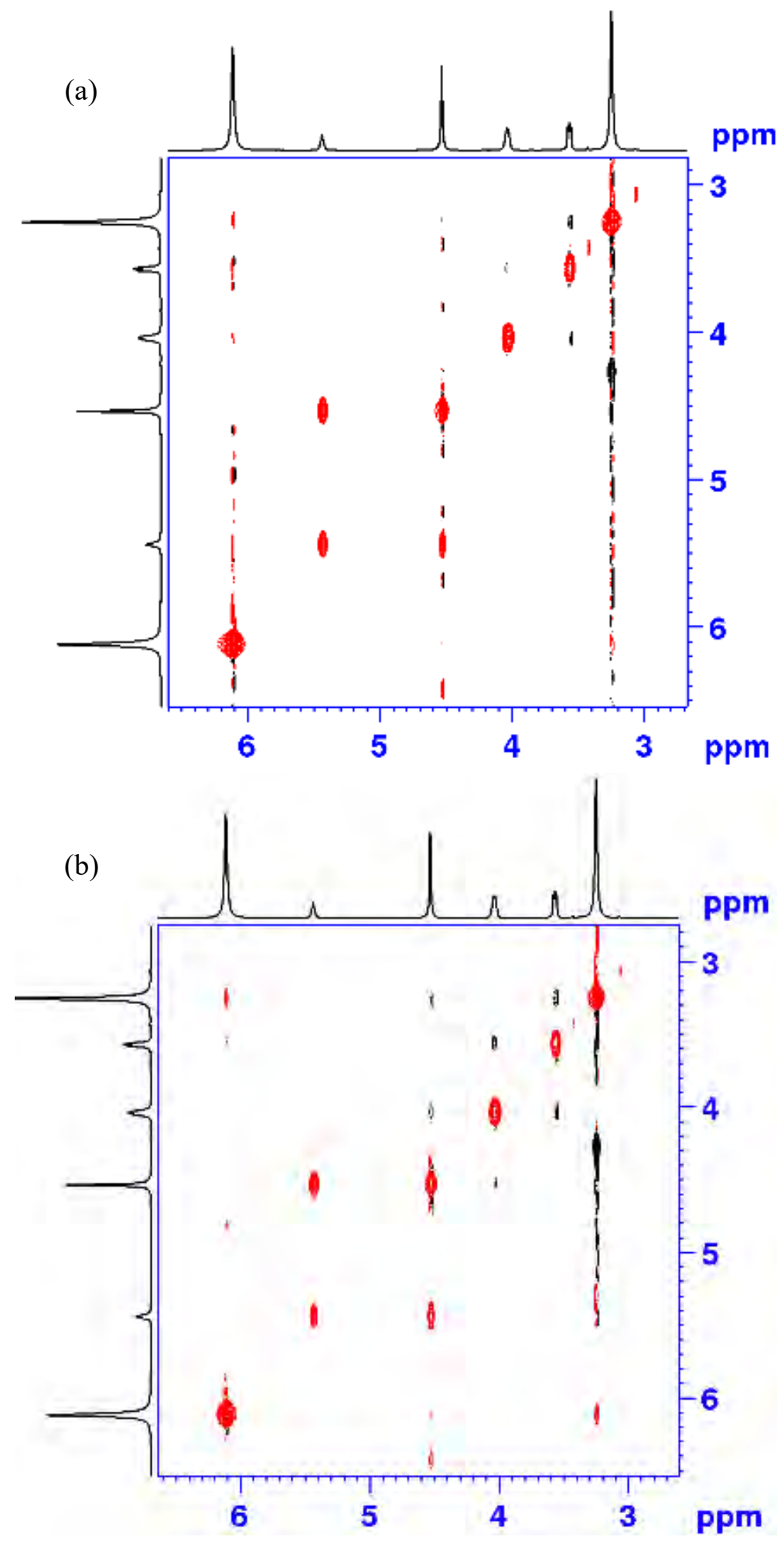

Figure S5. NOESY spectra of [Ch]Cl:U:W at $298 \mathrm{~K}$ and at several mixing times: (a) $t_{m i x}=$ $200 \mathrm{~ms}$; and (b) $t_{\text {mix }}=500 \mathrm{~ms}$. 


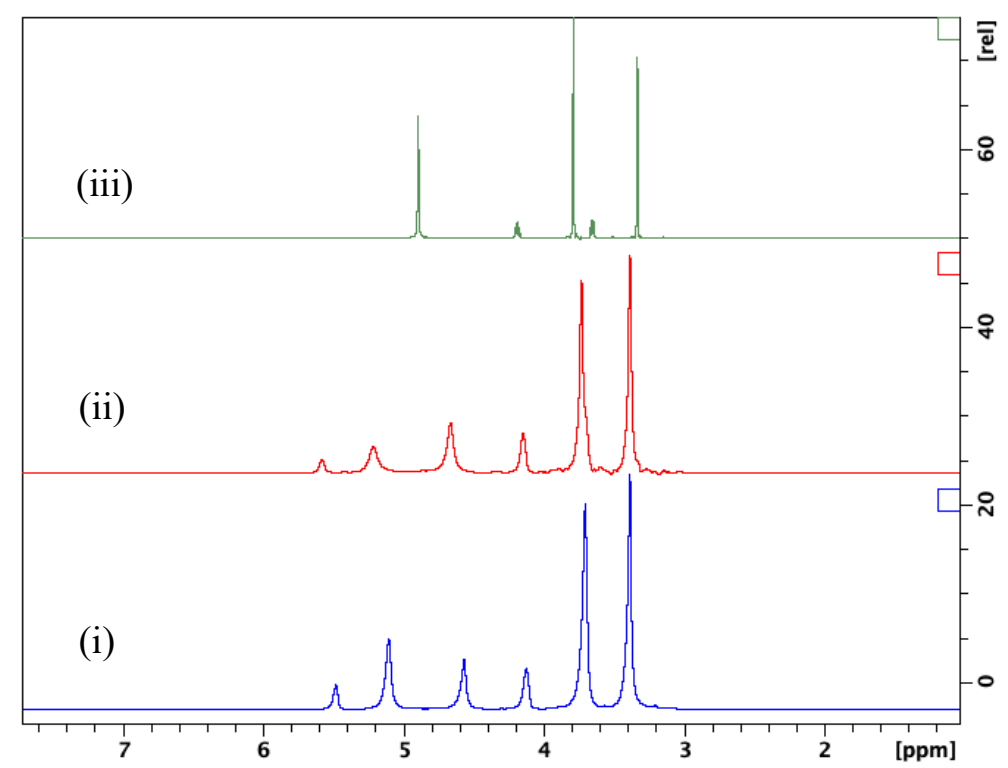

Figure S6a. ${ }^{1} \mathrm{H}-\mathrm{NMR} 400 \mathrm{MHz}$ spectra of [Ch]Cl:EG:W at $298 \mathrm{~K}$. i) neat eutectic; ii) $10 \% \mathrm{D}_{2} \mathrm{O}$; iii) $90 \% \mathrm{D}_{2} \mathrm{O}$.

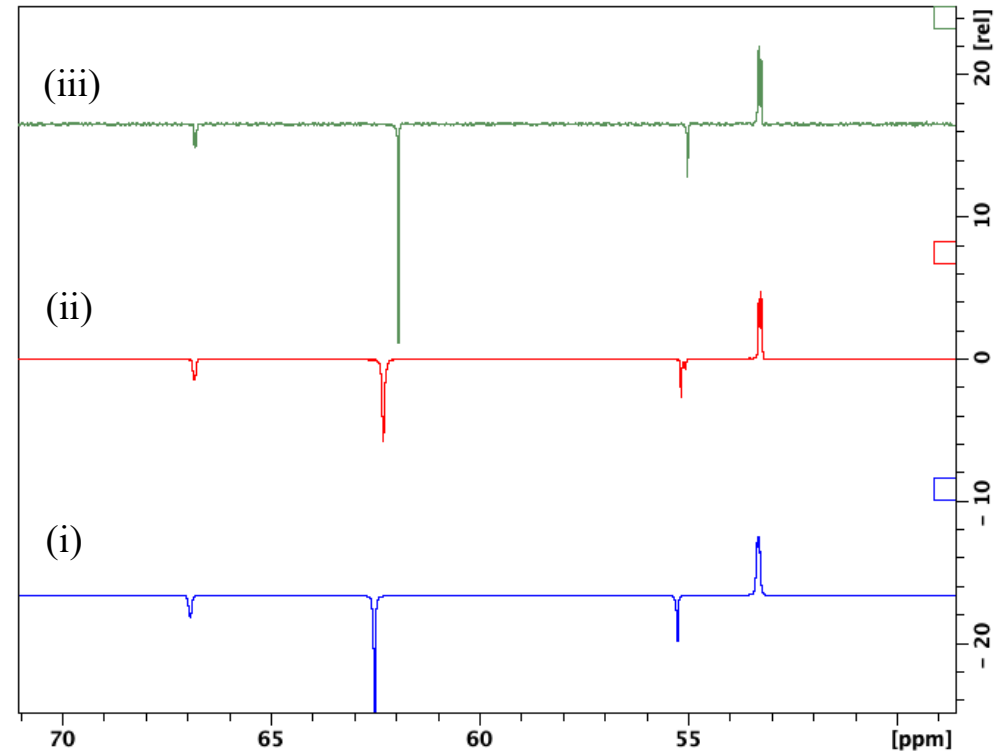

Figure S6b. ${ }^{13} \mathrm{C}$ spectra of $[\mathrm{Ch}] \mathrm{Cl}: \mathrm{EG}: \mathrm{W}$ at $298 \mathrm{~K}$. a) neat eutectic; b) $10 \% \mathrm{D}_{2} \mathrm{O}$; c) 90 $\% \mathrm{D}_{2} \mathrm{O}$. 

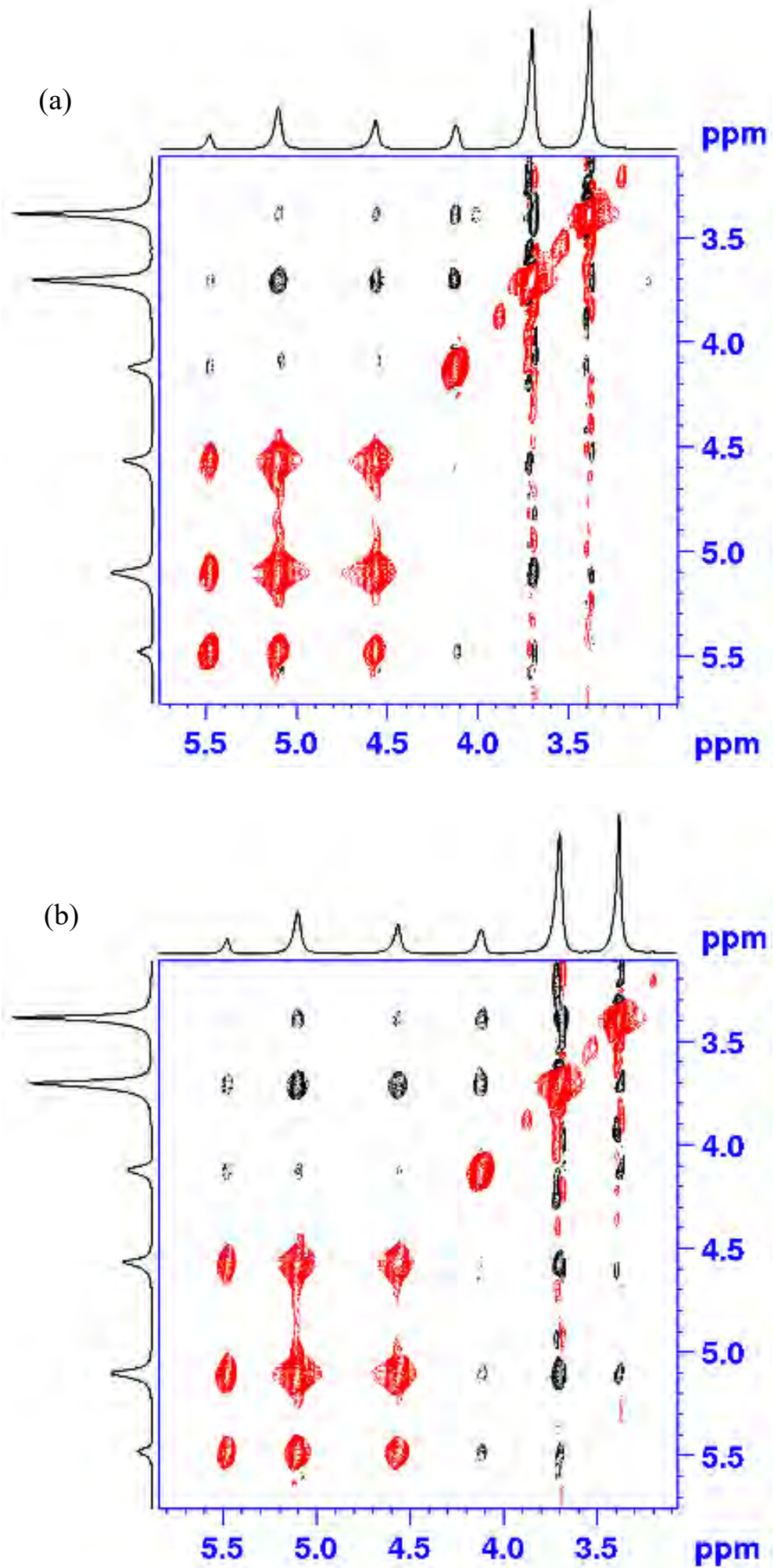

Figure S7. NOESY spectra of $[\mathrm{Ch}] \mathrm{Cl}: \mathrm{EG}: \mathrm{W}$ at $298 \mathrm{~K}$ and at several mixing times: (a) $t_{m i x}=200 \mathrm{~ms}$; and (b) $t_{\text {mix }}=500 \mathrm{~ms}$. 